Article

\title{
Synthesis of New Triarylpyrazole Derivatives
}

Possessing Terminal Sulfonamide Moiety and Their Inhibitory Effects on PGE 2 and Nitric Oxide Productions in Lipopolysaccharide-Induced RAW 264.7 Macrophages

Mohammed S. Abdel-Maksoud ${ }^{1}$, Mohammed I. El-Gamal 2,3,4 (D), Mahmoud M. Gamal El-Din ${ }^{1}$, Yunji Choi ${ }^{5}$, Jungseung Choi ${ }^{5}$, Ji-Sun Shin ${ }^{6,7}$, Shin-Young Kang ${ }^{6,7}$, Kyung Ho Yoo ${ }^{8}$, Kyung-Tae Lee ${ }^{6,7} \mathbb{D}$, Daejin Baek ${ }^{5, *}$ and Chang-Hyun Oh ${ }^{9,10, *}$

1 Medicinal \& Pharmaceutical Chemistry Department, Pharmaceutical and Drug Industries Research Division, National Research Centre (NRC), Dokki, Giza 12622, Egypt; ph_ss@hotmail.com (M.S.A.-M.); dr.m.g.eldin@hotmail.com (M.M.G.E.-D.)

2 Department of Medicinal Chemistry, College of Pharmacy, University of Sharjah, Sharjah 27272, UAE; drmelgamal2002@gmail.com

3 Sharjah Institute for Medical Research, University of Sharjah, Sharjah 27272, UAE

4 Department of Medicinal Chemistry, Faculty of Pharmacy, University of Mansoura, Mansoura 35516, Egypt

5 Department of Chemistry, Hanseo University, Seosan 31962, Korea; cossmoss@paran.com (Y.C.); djbaek@hanseo.ac.kr (J.C.)

6 Department of Pharmaceutical Biochemistry, College of Pharmacy, Kyung Hee University, Seoul 02792, Korea; jsshin@khu.ac.kr (J.-S.S.); kang940818@naver.com (S.-Y.K.); ktlee@khu.ac.kr (K.-T.L.)

7 Department of Life and Nanopharmaceutical Science, College of Pharmacy, Kyung Hee University, Seoul 130-650, Korea

8 Chemical Kinomics Research Center, Korea Institute of Science and Technology, Seoul 130-650, Korea; khyoo@kist.re.kr

9 Center for Biomaterials, Korea Institute of Science and Technology, Cheongryang, Seoul 130-650, Korea

10 Department of Biomolecular Science, University of Science and Technology, Daejeon, Yuseong-gu 34113, Korea

* Correspondence: djbaek@hanseo.ac.kr (D.B.); choh@kist.re.kr (C.-H.O.); Tel.: +82-010-8922-5160 (C.-H.O.); Fax: +82-41-660-1119 (C.-H.O.)

Received: 17 September 2018; Accepted: 2 October 2018; Published: 7 October 2018

check for updates

\begin{abstract}
This article describes the design, synthesis, and in vitro anti-inflammatory screening of new triarylpyrazole derivatives. A total of 34 new compounds were synthesized containing a terminal arylsulfonamide moiety and a different linker between the sulfonamide and pyridine ring at position 4 of the pyrazole ring. All the target compounds were tested for both cytotoxicity and nitric oxide (NO) production inhibition in lipopolysaccharide (LPS)-induced RAW 264.7 macrophages. Compounds 1b, 1d, 1g, 2a, and 2c showed the highest NO inhibition percentages and the lowest cytotoxic effect. The most potent derivatives were tested for their ability to inhibit prostaglandin $\mathrm{E}_{2}\left(\mathrm{PGE}_{2}\right)$ in LPS-induced RAW 264.7 macrophages. The $\mathrm{IC}_{50}$ for nitric oxide inhibition, $\mathrm{PGE}_{2}$ inhibition, and cell viability were determined. In addition, $\mathbf{1 b}, \mathbf{1 d}, \mathbf{1 g}, \mathbf{2} \mathbf{a}$, and $\mathbf{2 c}$ were tested for their inhibitory effect on LPS-induced inducible nitric oxide synthase (iNOS) and Cyclooxygenase 2 (COX-2) protein expression as well as iNOS enzymatic activity.
\end{abstract}

Keywords: anti-inflammatory; inducible nitric oxide synthase (iNOS); nitric oxide; prostaglandine $\mathrm{E}_{2}$; triarylpyrazole 


\section{Introduction}

Inflammation is one of the most important and complicated defense mechanisms. Inflammation participates in vital pathological and physiological processes like infection and wound healing [1]. As a result of tissue damage, many chemical intermediates are released in the damaged area. The chemical intermediates (such as E, L, and P-selectin and chemokines) initiate activation and migration of white blood cells to the damaged area. Eosinophils and neutrophils are the first leucocytes that migrate to the affected area followed by macrophages that release a number of cytokines and growth factors that affect the surrounding tissues [2-5]. Inflammation can be acute, occurring as part of a healing process, or chronic inflammation, which arises from the over response of the immune system and can lead to tissue damage. Chronic inflammation contributes to several physiological disorders such as neurodegenerative diseases [6], cancer [7], inflammatory bowel disease [8], and arteriosclerosis [9].

At the inflammation site, monocytes are converted to macrophages that release a large amount of nitric oxide (NO). Nitric oxide is produced as a result of oxidation of L-arginine by one of the nitric oxide synthase family members: endothelial nitric oxide synthase (eNOS), neuronal NOS (nNOS), which is a calcium-dependent enzyme, and inducible NOS (iNOS), which is calcium-independent enzyme) $[10,11]$. The presence of pro-inflammatory and chemical stimuli, such as lipopolysaccharide (LPS), leads to over-expression of iNOS [12]. Successful NO production inhibitory agents act through inhibition of iNOS protein expression and/or inhibition of iNOS enzymatic activity.

In addition to nitric oxide, prostaglandins are another important inflammation phospholipid by-product [13]. Prostaglandin $\mathrm{E}_{2}\left(\mathrm{PGE}_{2}\right)$ plays an important role in most inflammation conditions [14], such as glomerulonephritis, which may lead to renal failure [15]. The production of $\mathrm{PGE}_{2}$ is initiated by membrane phospholipids that are converted to arachidonic acid under the effect of the phospholipases enzyme. Arachidonic acid is transformed first to prostaglandin $\mathrm{H}_{2}$, which finally produces $\mathrm{PGE}_{2}$ [16]. The increase in both prostaglandin $\mathrm{E}_{2}$ and nitric oxide in chronic inflammation cases can lead to severe complicated physiological disorders $[17,18]$. So, the inhibition of both $\mathrm{PGE}_{2}$ and nitric oxide could result in the discovery of new anti-inflammatory drug candidates.

Several scaffolds have been investigated for their antiinflammatory activity, such as thiadiazole [19-21], chromones [22,23], triazoles [24], imidazole [25], and pyrazole. Many compounds with a pyrazole backbone have been proven to exhibit both anticancer [26-31] and antiinflammatory effects [32-35]. Celecoxib is an anti-inflammatory drug that contains diarylpyrazole as a back bone and works through inhibition of the COX-2 enzyme [36,37]. Previously, we reported the synthesis of a series of triarylpyrazoles [38-41], from which compound I (Figure 1) showed the highest activity for both nitric oxide and $\mathrm{PGE}_{2}$ production inhibition [40]. In the current work and based on our previous work, we synthesized a new series of triarylpyrazole derivatives. The new series contains 2-substituted pyridine at position 4 of the pyrazole ring. The substitutions contain a terminal sulfonamide moiety and a different linker between the sulfonamide and pyridine ring. The linker we used to investigate the effect of linker length on the activity was either ethylene or propylene. The new series was screened for its ability to inhibit nitric oxide; their cytotoxicity on RAW 264.7 macrophages was also investigated. The most potent compounds were tested for their inhibitory effect on $\mathrm{PGE}_{2}$ and iNOS expression. 


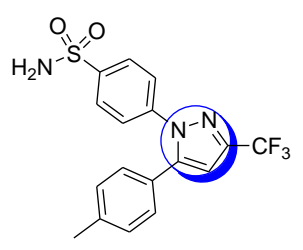

Celecoxib

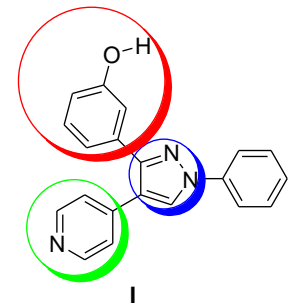

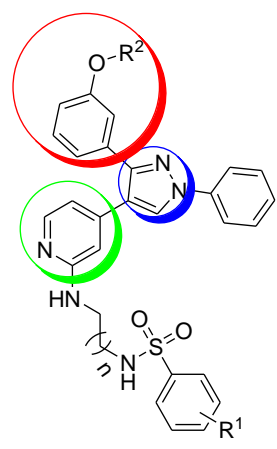

1a-i, 2a-i, 3a-h, and 4a-h

$n=1,2$

$\mathrm{R}^{1}=\mathrm{H}, p-\mathrm{Br}, p-\mathrm{Cl}, p-\mathrm{F}, p-\mathrm{OCH}_{3}$,

$p-\mathrm{CH}_{3}, p-\mathrm{CF}_{3}, m-\mathrm{F}$, fused benzene

$\mathrm{R}^{2}=\mathrm{H}, \mathrm{CH}_{3}$

Figure 1. General structures of the target compounds, Celecoxib, and previously-reported pyrazole compound [40].

\section{Results and Discussion}

\subsection{Chemistry}

The synthesis of the final target compounds $\mathbf{1 a}-\mathbf{i}, \mathbf{2} \mathbf{a}-\mathbf{i}, \mathbf{3 a}-\mathbf{h}$, and $\mathbf{4} \mathbf{a}-\mathbf{h}$ was achieved by adopting the synthetic strategy illustrated in Scheme 1 . We first synthesized the side chains $\mathbf{8 a}-\mathbf{i}$ and $\mathbf{9 a}-\mathbf{i}$. The main intermediate 5 was synthesized according to previously reported procedures [42,43]. Eventually, the target compounds $\mathbf{1 a}-\mathbf{i}$ and $\mathbf{2 a}-\mathbf{i}$ were obtained by coupling compound $\mathbf{5}$ with $\mathbf{8 a}-\mathbf{i}$ and $\mathbf{9 a}-\mathbf{i}$ using pyridine as a solvent and refluxing for $12 \mathrm{~h}$. Another pathway to obtain $\mathbf{1 a}-\mathbf{i}$ and $\mathbf{2 a}-\mathbf{i}$ was refluxing 5 with 1,2-ethylenediamine or 1,3-propylenediamine to produce 6 and 7, which, upon reaction with the appropriate arylsulfonyl chloride in the presence of triethylamine, produced the desired final compounds $\mathbf{1 a}-\mathbf{i}$ and $\mathbf{2 a}-\mathbf{i}$. Demethylation of compounds $\mathbf{1}$ and $\mathbf{2}$ using boron tribromide produced the hydroxyl final analogues $\mathbf{3 a}-\mathbf{h}$ and $\mathbf{4 a} \mathbf{a}-\mathbf{h}$ (Scheme 1). The structures of the final target compounds and their yields are represented in Table 1.

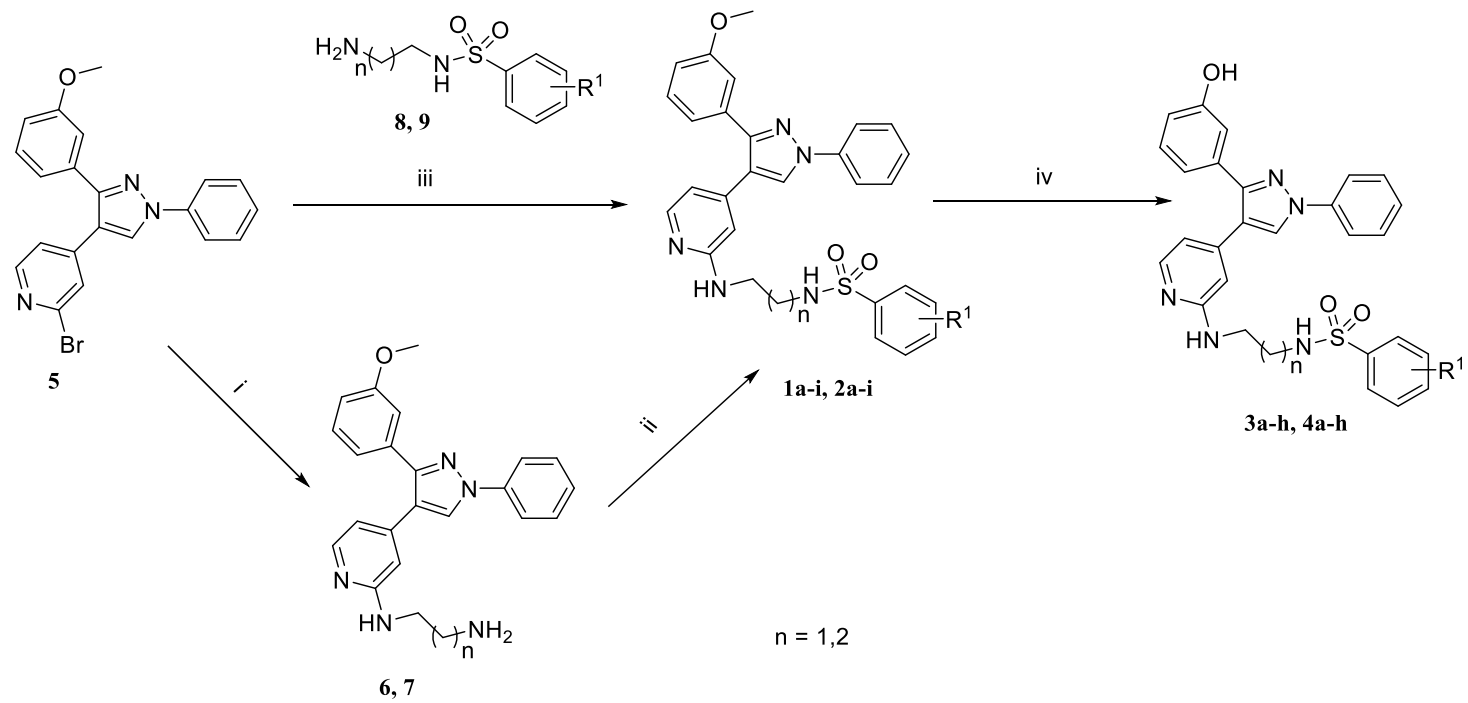

Scheme 1. Synthesis of final target compounds $\mathbf{1 a}-\mathbf{i}, \mathbf{2} \mathbf{a}-\mathbf{i}, \mathbf{3 a}-\mathbf{h}$, and $\mathbf{4 a - h}$. Reagents and conditions: (i) 1,2-ethylenediamine or 1,3-propylenediamine, reflux $8 \mathrm{~h}$; (ii) appropriate aryl sulfonyl chloride, Triethylamine, Dichloromethane, $0^{\circ} \mathrm{C}$, overnight; (iii) pyridine, $8 \mathbf{a}-\mathbf{i}$ or $\mathbf{9 a}-\mathbf{i}$, reflux $12 \mathrm{~h}$; and (vii) $\mathrm{BBr}_{3}$, $\mathrm{DCM},-78^{\circ} \mathrm{C} ; 0^{\circ} \mathrm{C}$, overnight. 
Table 1. Structures and yields of the final target compounds.

\begin{tabular}{|c|c|c|c|c|c|c|c|c|c|}
\hline Compound & $\mathbf{n}$ & $\mathbf{R}^{1}$ & $\mathbf{R}^{2}$ & Yield & Compound & $\mathbf{n}$ & $\mathbf{R}^{1}$ & $\mathbf{R}^{2}$ & Yield \\
\hline 1a & 1 & $\mathrm{CH}_{3}$ & $\mathrm{H}$ & $65 \%$ & $3 \mathbf{a}$ & 1 & $\mathrm{H}$ & $\mathrm{H}$ & $36 \%$ \\
\hline $1 b$ & 1 & $\mathrm{CH}_{3}$ & $4-\mathrm{Br}$ & $61 \%$ & $3 b$ & 1 & $\mathrm{H}$ & $4-\mathrm{Br}$ & $30 \%$ \\
\hline 1c & 1 & $\mathrm{CH}_{3}$ & $4-\mathrm{Cl}$ & $60 \%$ & $3 c$ & 1 & $\mathrm{H}$ & $4-\mathrm{Cl}$ & $41 \%$ \\
\hline $1 d$ & 1 & $\mathrm{CH}_{3}$ & 4-F & $67 \%$ & $3 d$ & 1 & $\mathrm{H}$ & 4-F & $40 \%$ \\
\hline 1e & 1 & $\mathrm{CH}_{3}$ & $\mathrm{p}-\mathrm{OCH}_{3}$ & $62 \%$ & $3 e$ & 1 & $\mathrm{H}$ & $4-\mathrm{CH}_{3}$ & $38 \%$ \\
\hline 1f & 1 & $\mathrm{CH}_{3}$ & $4-\mathrm{CH}_{3}$ & $69 \%$ & $3 f$ & 1 & $\mathrm{H}$ & $4-\mathrm{CF}_{3}$ & $40 \%$ \\
\hline $1 \mathrm{~g}$ & 1 & $\mathrm{CH}_{3}$ & $4-\mathrm{CF}_{3}$ & $74 \%$ & $3 g$ & 1 & $\mathrm{H}$ & 3-F & $32 \%$ \\
\hline 1h & 1 & $\mathrm{CH}_{3}$ & $3-\mathrm{F}$ & $66 \%$ & $3 h$ & 1 & $\mathrm{H}$ & $\begin{array}{c}\text { Fused } \\
\text { benzene }\end{array}$ & $33 \%$ \\
\hline $1 \mathbf{i}$ & 1 & $\mathrm{CH}_{3}$ & $\begin{array}{c}\text { Fused } \\
\text { benzene }\end{array}$ & $71 \%$ & $4 a$ & 2 & $\mathrm{H}$ & $\mathrm{H}$ & $37 \%$ \\
\hline $2 a$ & 2 & $\mathrm{CH}_{3}$ & $\mathrm{H}$ & $60 \%$ & $4 b$ & 2 & $\mathrm{H}$ & $4-\mathrm{Br}$ & $42 \%$ \\
\hline $2 b$ & 2 & $\mathrm{CH}_{3}$ & $4-\mathrm{Br}$ & $62 \%$ & $4 c$ & 2 & $\mathrm{H}$ & $4-\mathrm{Cl}$ & $52 \%$ \\
\hline $2 c$ & 2 & $\mathrm{CH}_{3}$ & $4-\mathrm{Cl}$ & $62 \%$ & $4 d$ & 2 & $\mathrm{H}$ & $4-F$ & $43 \%$ \\
\hline $2 d$ & 2 & $\mathrm{CH}_{3}$ & 4-F & $75 \%$ & $4 e$ & 2 & $\mathrm{H}$ & $4-\mathrm{CH}_{3}$ & $33 \%$ \\
\hline $2 e$ & 2 & $\mathrm{CH}_{3}$ & 4-OCH3 & $71 \%$ & $4 f$ & 2 & $\mathrm{H}$ & $4-\mathrm{CF}_{3}$ & $39 \%$ \\
\hline $2 f$ & 2 & $\mathrm{CH}_{3}$ & $4-\mathrm{CH}_{3}$ & $72 \%$ & $4 g$ & 2 & $\mathrm{H}$ & 3-F & $41 \%$ \\
\hline $2 \mathrm{~g}$ & 2 & $\mathrm{CH}_{3}$ & $4-\mathrm{CF}_{3}$ & $71 \%$ & $4 h$ & 2 & $\mathrm{H}$ & $\begin{array}{c}\text { Fused } \\
\text { benzene }\end{array}$ & $40 \%$ \\
\hline $2 \mathrm{~h}$ & 2 & $\mathrm{CH}_{3}$ & 3-F & $76 \%$ & & & & & \\
\hline $2 \mathbf{i}$ & 2 & $\mathrm{CH}_{3}$ & $\begin{array}{l}\text { Fused } \\
\text { benzene }\end{array}$ & $66 \%$ & & & & & \\
\hline
\end{tabular}

\subsection{Biology}

The ability of a certain molecule to inhibit the production of inflammatory mediator(s) is one of successful approach to treatment both chronic and acute inflammation. The final target compounds $\mathbf{1 a}-\mathbf{i}, \mathbf{2 a}-\mathbf{i}, \mathbf{3 a}-\mathbf{h}$, and $\mathbf{4 a}-\mathbf{h}$ were tested for their ability to inhibit NO release in LPS-induced RAW 264.7 macrophages at three different concentrations (Table 2).

Table 2. Nitric oxide production inhibition of the final target compounds at different dose levels.

\begin{tabular}{cccc}
\hline \multirow{2}{*}{ Compound } & \multicolumn{3}{c}{ Nitric Oxide \% Inhibition } \\
\cline { 2 - 4 } $\mathbf{1 a}$ & $17.35 \pm 0.09$ & $\mathbf{5} \boldsymbol{\mu \mathbf { M }}$ & $\mathbf{1 0} \boldsymbol{\mu \mathbf { M }}$ \\
\hline $\mathbf{1 b}$ & $12.05 \pm 0.11$ & $24.23 \pm 0.98$ & $52.93 \pm 3.12$ \\
$\mathbf{1 c}$ & $13.27 \pm 0.08$ & $24.76 \pm 0.17$ & $49.89 \pm 1.25$ \\
$\mathbf{1 d}$ & $19.79 \pm 0.14$ & $29.36 \pm 0.77$ & $61.28 \pm 1.33$ \\
$\mathbf{1 e}$ & $13.52 \pm 0.11$ & $16.10 \pm 0.09$ & $41.47 \pm 0.99$ \\
$\mathbf{1 f}$ & $16.29 \pm 0.10$ & $26.54 \pm 0.65$ & $53.09 \pm 2.10$ \\
$\mathbf{1 g}$ & $10.98 \pm 0.07$ & $23.62 \pm 0.54$ & $60.80 \pm 1.75$ \\
$\mathbf{1 h}$ & $11.12 \pm 0.02$ & $26.24 \pm 0.99$ & $41.25 \pm 2.15$ \\
$\mathbf{1 i}$ & $13.40 \pm 0.18$ & $19.90 \pm 0.24$ & $51.51 \pm 0.14$ \\
$\mathbf{2 a}$ & $0.17 \pm 0.03$ & $30.20 \pm 0.27$ & $62.76 \pm 3.25$ \\
$\mathbf{2 b}$ & $0.01 \pm 0.03$ & $28.06 \pm 0.66$ & $52.44 \pm 1.62$ \\
$\mathbf{2 c}$ & $0.02 \pm 0.01$ & $24.69 \pm 0.81$ & $59.09 \pm 0.93$ \\
$\mathbf{2 d}$ & $7.81 \pm 0.03$ & $23.03 \pm 0.89$ & $55.00 \pm 4.01$ \\
$\mathbf{2 e}$ & $2.02 \pm 0.01$ & $23.90 \pm 1.12$ & $50.20 \pm 1.88$ \\
$\mathbf{2 f}$ & $4.36 \pm 0.04$ & $19.76 \pm 0.96$ & $46.32 \pm 3.21$ \\
$\mathbf{2 g}$ & $2.91 \pm 0.02$ & $26.26 \pm 1.01$ & $56.03 \pm 0.89$ \\
$\mathbf{2 h}$ & $4.87 \pm 0.05$ & $24.07 \pm 0.91$ & $41.54 \pm 1.12$ \\
$\mathbf{2 i}$ & $16.15 \pm 0.12$ & $25.75 \pm 0.49$ & $51.93 \pm 1.93$ \\
$\mathbf{3 a}$ & $4.78 \pm 0.03$ & $21.49 \pm 0.37$ & $48.97 \pm 1.10$ \\
$\mathbf{3 b}$ & $15.82 \pm 0.16$ & $24.36 \pm 0.52$ & $48.69 \pm 1.74$ \\
$\mathbf{3 c}$ & $6.34 \pm 0.06$ & $11.68 \pm 0.71$ & $33.81 \pm 0.89$ \\
\hline
\end{tabular}


Table 2. Cont.

\begin{tabular}{|c|c|c|c|}
\hline \multirow{2}{*}{ Compound } & \multicolumn{3}{|c|}{ Nitric Oxide \% Inhibition } \\
\hline & $1 \mu \mathrm{M}$ & $5 \mu \mathbf{M}$ & $10 \mu \mathrm{M}$ \\
\hline $3 d$ & $10.58 \pm 0.09$ & $18.31 \pm 0.26$ & $48.18 \pm 0.74$ \\
\hline $3 e$ & $7.15 \pm 0.04$ & $12.40 \pm 0.72$ & $31.43 \pm 0.33$ \\
\hline $3 f$ & $6.08 \pm 0.07$ & $15.21 \pm 0.91$ & $36.51 \pm 0.59$ \\
\hline $3 g$ & $16.19 \pm 0.17$ & $19.06 \pm 0.89$ & $37.68 \pm 0.85$ \\
\hline $3 h$ & $10.33 \pm 0.08$ & $14.72 \pm 0.42$ & $16.07 \pm 0.48$ \\
\hline $4 a$ & $11.11 \pm 0.10$ & $24.13 \pm 0.56$ & $59.25 \pm 1.31$ \\
\hline $4 b$ & $8.19 \pm 0.06$ & $22.18 \pm 0.72$ & $63.82 \pm 2.14$ \\
\hline $4 \mathrm{c}$ & $0.86 \pm 0.09$ & $22.02 \pm 0.42$ & $46.95 \pm 1.34$ \\
\hline $4 d$ & $9.02 \pm 0.03$ & $20.84 \pm 0.36$ & $48.49 \pm 1.79$ \\
\hline $4 e$ & $0.69 \pm 0.01$ & $18.57 \pm 0.98$ & $59.69 \pm 0.70$ \\
\hline $4 f$ & $4.87 \pm 0.14$ & $18.87 \pm 1.02$ & $53.82 \pm 1.87$ \\
\hline $4 \mathrm{~g}$ & ND & $29.49 \pm 0.86$ & $51.15 \pm 1.45$ \\
\hline $4 h$ & $0.97 \pm 0.01$ & $21.04 \pm 0.22$ & $50.21 \pm 2.01$ \\
\hline L-NIL $(40 \mu \mathrm{M})$ & & $77.89 \pm 4.25$ & \\
\hline
\end{tabular}

ND: Not determined.

The tested derivatives exhibited diverse activity for NO production inhibition. All compounds inhibited NO release in a dose-dependent manner. For series 1a-i, most of the compounds inhibited the production of NO by $50 \%$ or more at $10 \mu \mathrm{M}$. Compound $\mathbf{1 b}$ ( $p$-bromo) showed the highest inhibition at $68.66 \%$ followed by $1 \mathbf{d}$ ( $p$-flouro) with inhibition of $61.28 \%$, then $\mathbf{1 g}\left(p-\mathrm{CF}_{3}\right)$ with inhibition $60.80 \%$. Compound 1a, 1f, and $1 \mathbf{i}$ had moderate activity with $52.93 \%, 53.09 \%$, and $51.51 \%$ inhibition, respectively. Regarding compounds $\mathbf{2 a}-\mathbf{i}$, the highest inhibition was obtained from compounds 2a $(62.76 \%), 2$ c $(59.09 \%), 2$ g $(56.03 \%), 2 d(55.00 \%)$, and $\mathbf{2 b}(52.44 \%)$. Generally for methoxy series, derivatives with ethylene bridges were more active compared to compounds with propylene bridges. In addition, compounds with electron-withdrawing groups were more potent compared to compounds with electron-donating groups, and para substitutions were slightly more active than meta substitutions. The electronic nature and the position of the substituents were other important factors that confer optimum affinity to the receptor site.

Derivatives containing hydroxyl group, $3 \mathbf{a}-\mathbf{h}$ and $\mathbf{4 a}-\mathbf{h}$, were less active compared to methoxy derivatives. The highest percent inhibition for $\mathbf{3 a}-\mathbf{h}$ was exhibited by $3 a(48.97 \%)$. Series $\mathbf{4 a}-\mathbf{h}$ showed good inhibition with the highest demonstrated by compound $4 \mathbf{b}(63.85 \%)$ followed by $4 \mathbf{e}(59.69 \%), 4 \mathbf{a}(59.25 \%), \mathbf{4 f}(53.82 \%)$, and $4 \mathbf{g}(51.15 \%)$, as illustrated in Table 2 . The methoxy group is more hydrophobic and bulkier than hydroxyl, and this might affect the activity by enhancing the molecule's ability to cross the cell membrane and/or increasing the affinity with the target receptor site. Furthermore, the most active compounds (e.g., 1b) were more active than the lead compound possessing no tether on the pyridyl ring [33]. So, this side chain is an important contributor to the inhibition activity, which could improve the molecular affinity to its receptor site.

In addition to NO inhibition, the cytotoxic activity of compounds $\mathbf{1 a}-\mathbf{i}, \mathbf{2} \mathbf{a}-\mathbf{i}, \mathbf{3} \mathbf{a}-\mathbf{h}$, and 4a-h in RAW 264.7 macrophages were measured using the 3-(4,5-dimethylthiazol-2-yl)2,5-diphenyltetrazolium bromide (MTT) assay to check whether the effects on the production of $\mathrm{NO}$ was caused by nonspecific cytotoxicity. The $\mathrm{IC}_{50}$ values for both nitric oxide inhibition and cell viability are presented in Table 3. 
Table 3. $\mathrm{IC}_{50}(\mu \mathrm{M})$ for nitric oxide production and cell viability of final target compounds.

\begin{tabular}{|c|c|c|}
\hline Compound & $\operatorname{NO}\left(\mathrm{IC}_{50}\right)^{\mathrm{a}}$ & Cytotoxicity $\left(\mathrm{IC}_{50}\right)^{\mathrm{a}}$ \\
\hline 1a & $9.17 \pm 0.52$ & $245.78 \pm 1.91$ \\
\hline $1 b$ & $7.90 \pm 0.41$ & $254.15 \pm 2.54$ \\
\hline 1c & $10.10 \pm 0.63$ & $219.39 \pm 0.14$ \\
\hline 1d & $8.23 \pm 0.32$ & $169.15 \pm 1.64$ \\
\hline 1e & $13.40 \pm 0.72$ & $285.41 \pm 4.18$ \\
\hline 1f & $9.42 \pm 0.12$ & $291.01 \pm 1.12$ \\
\hline $1 g$ & $8.55 \pm 0.14$ & $261.57 \pm 1.57$ \\
\hline $1 \mathrm{~h}$ & $12.62 \pm 0.29$ & $244.21 \pm 2.23$ \\
\hline $\mathbf{1 i}$ & $9.76 \pm 0.21$ & $>400$ \\
\hline $2 a$ & $8.04 \pm 0.09$ & $346.2 \pm 4.21$ \\
\hline $2 b$ & $9.50 \pm 0.34$ & $384.69 \pm 1.29$ \\
\hline $2 c$ & $8.68 \pm 0.22$ & $289.92 \pm 1.87$ \\
\hline $2 d$ & $12.42 \pm 0.40$ & $260.32 \pm 2.24$ \\
\hline $2 e$ & $9.96 \pm 0.18$ & $>400$ \\
\hline $2 f$ & $9.16 \pm 0.27$ & $322.54 \pm 3.35$ \\
\hline $2 g$ & $10.45 \pm 0.44$ & $252.64 \pm 1.87$ \\
\hline $2 \mathrm{~h}$ & $9.19 \pm 0.25$ & $245.78 \pm 2.71$ \\
\hline $2 \mathbf{i}$ & $9.63 \pm 0.48$ & $>400$ \\
\hline $3 a$ & $10.29 \pm 0.23$ & $29.75 \pm 1.91$ \\
\hline $3 b$ & $10.55 \pm 0.51$ & $24.31 \pm 0.41$ \\
\hline $3 c$ & $15.21 \pm 0.17$ & $22.69 \pm 0.30$ \\
\hline $3 d$ & $10.72 \pm 0.52$ & $26.58 \pm 0.47$ \\
\hline $3 e$ & $16.14 \pm 0.72$ & $32.52 \pm 0.75$ \\
\hline $3 f$ & $22.21 \pm 0.31$ & $24.15 \pm 1.61$ \\
\hline $3 g$ & $21.42 \pm 0.17$ & $28.74 \pm 0.74$ \\
\hline $3 h$ & $>30$ & $100.21 \pm 1.21$ \\
\hline $4 a$ & $8.86 \pm 0.36$ & $16.58 \pm 0.91$ \\
\hline $4 b$ & $8.34 \pm 0.11$ & $19.54 \pm 0.49$ \\
\hline $4 c$ & $13.25 \pm 0.52$ & $18.79 \pm 0.68$ \\
\hline $4 d$ & $11.32 \pm 0.16$ & $12.58 \pm 0.22$ \\
\hline $4 e$ & $8.82 \pm 0.32$ & $22.96 \pm 0.63$ \\
\hline $4 f$ & $9.45 \pm 0.15$ & $17.73 \pm 0.61$ \\
\hline $4 g$ & $8.24 \pm 0.41$ & $9.35 \pm 0.32$ \\
\hline $4 h$ & $9.96 \pm 0.48$ & $10.92 \pm 0.22$ \\
\hline L-NIL & $29.32 \pm 0.15$ & ND \\
\hline
\end{tabular}

a Values represent means \pm SD of three independent experiments; ND: Not determined.

Compounds $1 \mathbf{1}-\mathbf{i}$ and $\mathbf{2 a}-\mathbf{i}$ had high $\mathrm{IC}_{50}$ values in the cell viability test and all compounds had an $\mathrm{IC}_{50}$ of more than $169 \mu \mathrm{M}$. The $\mathrm{IC}_{50}$ for nitric oxide production inhibition was less than $14 \mu \mathrm{M}$. The most potent compound among the methoxy derivatives was $\mathbf{1 b}$ with an $\mathrm{IC}_{50}$ of $7.90 \mu \mathrm{M}$ followed by $2 \mathrm{a}, 1 \mathrm{~d}$, and $2 \mathrm{c}$ with $\mathrm{IC}_{50}$ values of $8.04,8.2$, and $8.68 \mu \mathrm{M}$, respectively. These most potent molecules showed extreme safety expressed by very high $\mathrm{IC}_{50}$ values as cytotoxic agents. This means that their inhibitory effect against NO production is not due to the cytotoxic effect. Compounds $\mathbf{3 a}-\mathbf{h}$ and $\mathbf{4 a}-\mathbf{h}$ showed cytotoxic effects at low doses and the $\mathrm{IC}_{50} \mathrm{~s}$ for nitric oxide inhibition were close to the $\mathrm{IC}_{50} \mathrm{~s}$ of the cell viability test. From Table 3, it can be predicted that the inhibitory effect of hydroxyl-containing compounds is due to the cytotoxic effect.

Compounds $\mathbf{1 b}, \mathbf{1 d}, \mathbf{1 g}, \mathbf{2 a}$, and $\mathbf{2 c}$, which exhibited the highest activities regarding nitric oxide inhibition and the highest $\mathrm{IC}_{50}$ values in the cell viability test, were investigated for their ability to inhibit $\mathrm{PGE}_{2}$ production in LPS-induced RAW 264.7 macrophages at 1, 5, and $10 \mu \mathrm{M}$. The investigation results are shown in Table 4 . Compounds $\mathbf{1 b}, \mathbf{1 g}, \mathbf{2} \mathbf{a}$, and $\mathbf{2 c}$ were able to inhibit more than $50 \%$ of the prostaglandin production at a dose $5 \mu \mathrm{M}$. The five compounds were able to reduce $\mathrm{PGE}_{2}$ production by over $75 \%$ at a dose of $10 \mu \mathrm{M}$. Compound $1 \mathrm{~g}$ was the most potent compound with an $\mathrm{IC}_{50}$ of $4.55 \mu \mathrm{M}$ followed by $\mathbf{2 c}, \mathbf{1 b}, \mathbf{2 a}$, and $\mathbf{1 d}$ with $\mathrm{IC}_{50}$ values of $4.68,4.72,4.87$, and $5.06 \mu \mathrm{M}$, respectively. 
Table 4. Inhibitory effect and $\mathrm{IC}_{50}$ values of compounds $\mathbf{1 b}, \mathbf{1 d}, \mathbf{1 g}, \mathbf{2} \mathbf{a}$, and $\mathbf{2 c}$ on prostaglandin E2 $\left(\mathrm{PGE}_{2}\right)$ production.

\begin{tabular}{ccccc}
\hline \multirow{2}{*}{ Compound } & \multicolumn{4}{c}{ PGE $_{\mathbf{2}}$ Inhibition (\%) } \\
\cline { 2 - 5 } & $\mathbf{1} \boldsymbol{\mu} \mathbf{M}$ & $\mathbf{5} \boldsymbol{\mu} \mathbf{M}$ & $\mathbf{1 0} \boldsymbol{\mu M}$ & IC $_{\mathbf{5 0}}(\boldsymbol{\mu} \mathbf{M})$ \\
\hline $\mathbf{1 b}$ & $16.24 \pm 0.79$ & $52.56 \pm 2.21$ & $76.92 \pm 1.34$ & $4.75 \pm 0.25$ \\
$\mathbf{1 d}$ & $10.26 \pm 0.81$ & $49.57 \pm 1.25$ & $85.75 \pm 2.64$ & $5.06 \pm 0.21$ \\
$\mathbf{1 g}$ & $19.94 \pm 0.89$ & $53.85 \pm 1.91$ & $79.34 \pm 2.19$ & $4.55 \pm 0.39$ \\
$\mathbf{2 a}$ & $31.09 \pm 1.14$ & $50.70 \pm 0.99$ & $76.89 \pm 4.99$ & $4.87 \pm 0.44$ \\
$\mathbf{2 c}$ & $17.51 \pm 1.51$ & $52.80 \pm 2.01$ & $81.37 \pm 2.94$ & $4.68 \pm 0.37$ \\
$\mathbf{N S - 3 9 8}$ & $90.53 \pm 0.53$ & $95.78 \pm 0.67$ & $98.25 \pm 1.50$ & $6.25 \times 10^{-3} \pm 0.41 \times 10^{-3}$ \\
\hline
\end{tabular}

${ }^{a}$ Values represent means \pm SD of three independent experiments.

The cumulative activities of compounds $\mathbf{1 b}, \mathbf{1 d}, \mathbf{1 g}, \mathbf{2 a}$, and $\mathbf{2 c}$ are illustrated in Figure 2 using $\mathrm{N}$-(2-cyclohexyloxy-4-nitrophenyl)methanesulfonamide (NS398) and $\mathrm{N}^{6}$-(1-Iminoethyl)-L-lysine (L-NIL) as standard compounds for $\mathrm{PGE}_{2}$ production inhibition and NO production inhibition, respectively. The tested compounds showed low cytotoxic activity in the viability test. A significant reduction in both nitric oxide and $\mathrm{PGE}_{2}$ production was observed starting from $5 \mu \mathrm{M}$. At $20 \mu \mathrm{M}$, the production of both inflammatory mediators was restored to normal levels.

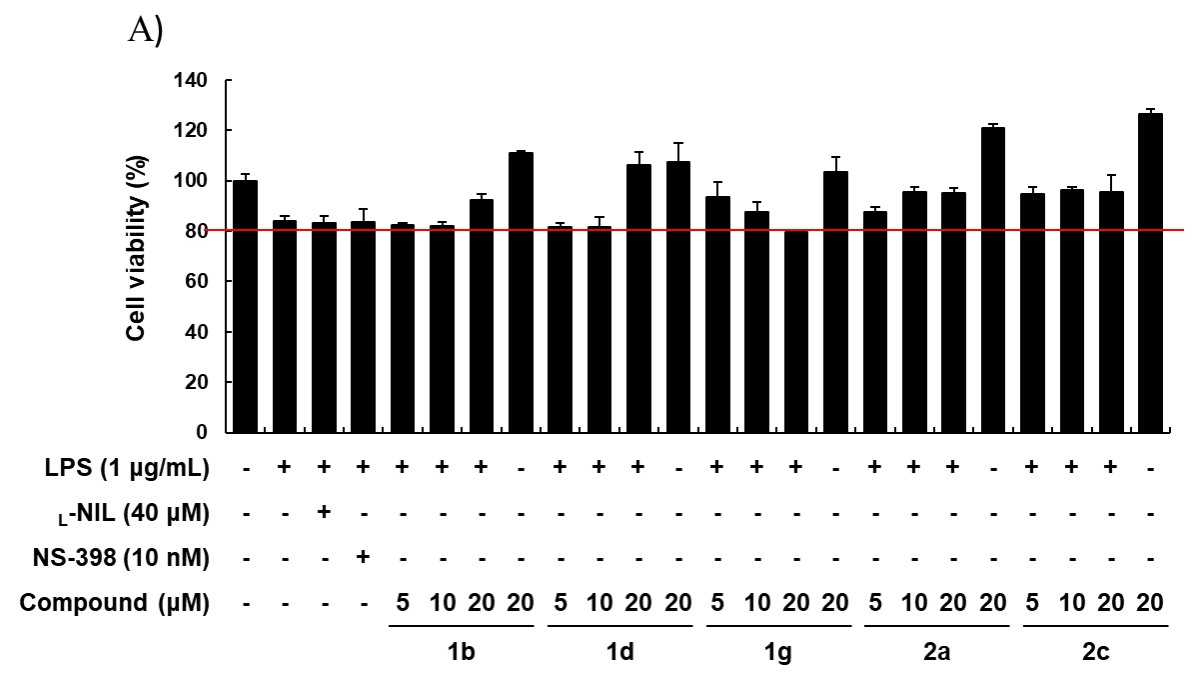

Figure 2. Cont. 
B)
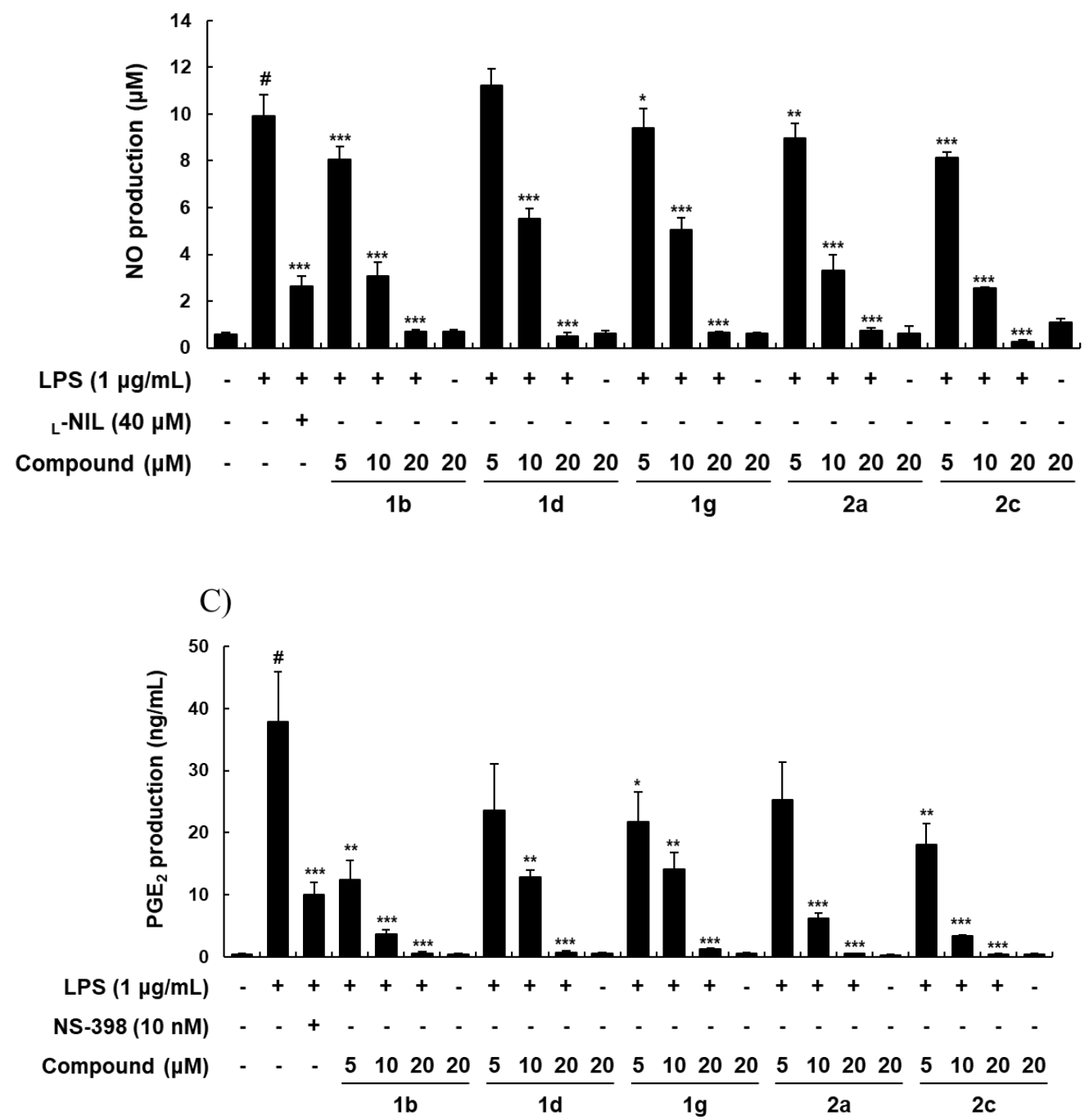

Figure 2. (A) In vitro cytotoxicity, (B) nitric oxide inhibition, and (C) prostaglandin $\mathrm{E}_{2}$ inhibition of compounds $\mathbf{1 b}, \mathbf{1 d}, \mathbf{1 g}, \mathbf{2 a}$, and $\mathbf{2 c}$. Data are presented as the means \pm SD of three independent experiments. \# $p<0.05$ versus the control cells; ${ }^{* * *} p<0.001$ versus lipopolysaccharide-stimulated cells; ${ }^{* *} p<0.05$ versus lipopolysaccharide-stimulated cells; * statistical significances were compared using ANOVA and Dunnett's post hoc test.

As a result of their activity against both $\mathrm{NO}$ and $\mathrm{PGE}_{2}$ production and low cellular toxicity, compounds $\mathbf{1 b}, \mathbf{1 d}, \mathbf{1 g}, \mathbf{2 a}$, and $\mathbf{2 c}$ were tested for their inhibitory effect on the expression of both iNOS and COX-2. The cellular lysates were prepared from the with- and without-pretreatment tested compounds $(5,10,20 \mu \mathrm{M})$ for one hour and then with LPS $(1 \mu \mathrm{g} / \mathrm{mL})$ for $24 \mathrm{~h}$, using $\beta$-actin as a reference. The results are shown in Figure 3. Compound 1g, possessing an ethylene spacer, 3-methoxyphenyl at position 3 of the pyrazole ring, and a $p$-(trifluoromethyl)phenyl terminal ring, showed complete inhibition of iNOS expression at $20 \mu \mathrm{M}$. Compounds $\mathbf{1 b}$ and $\mathbf{1 d}$ exhibited a partial inhibitory effect against iNOS at the same concentration (Figures 3 and 4). Compound $1 \mathbf{g}$ might express its inhibitory effect on NO production mainly through inhibition of iNOS protein expression and partially through inhibition of iNOS enzyme activity. 


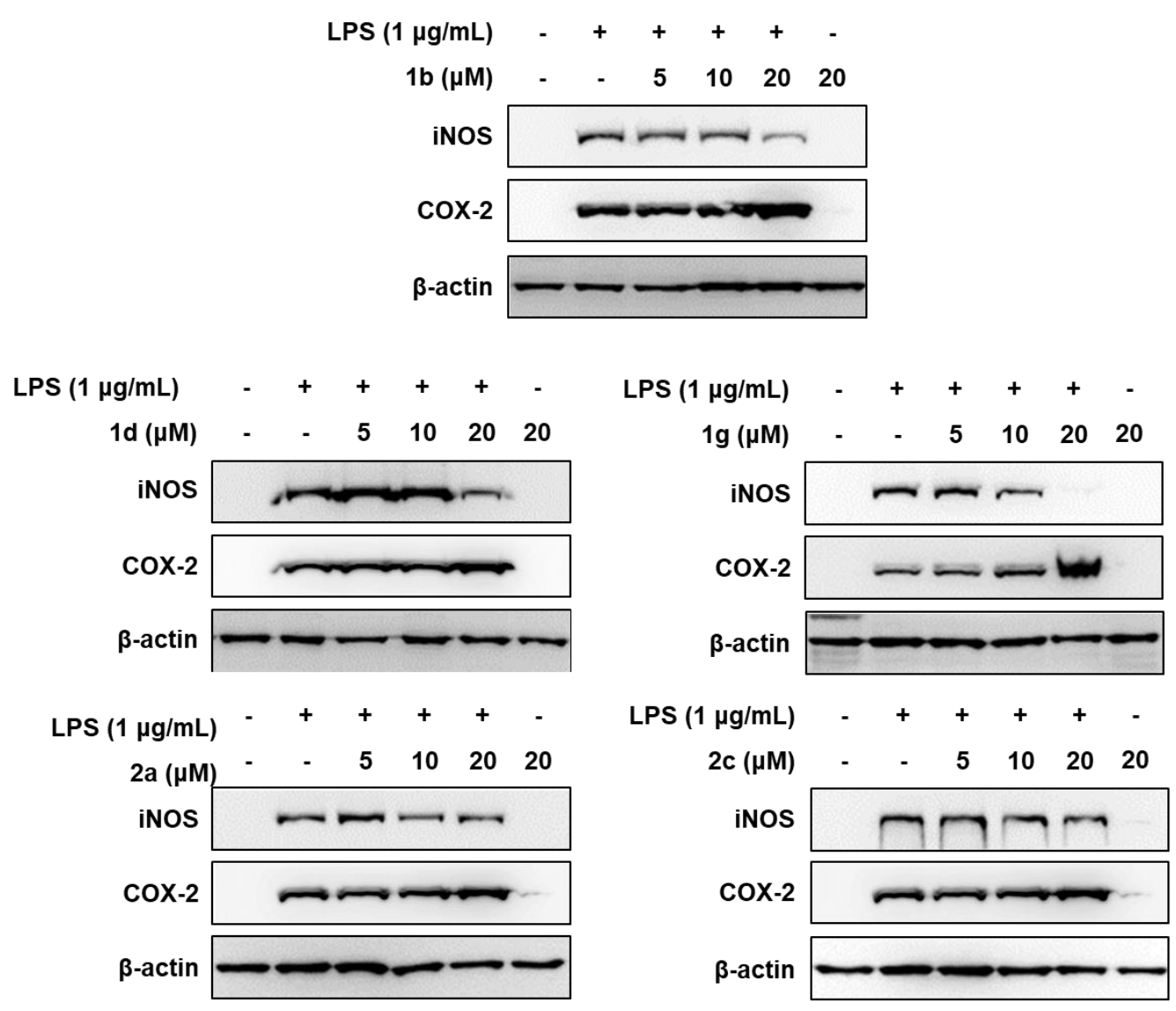

Figure 3. Inhibitory activity of compounds $\mathbf{1 b}, \mathbf{1 d}, \mathbf{1 g}, \mathbf{2 a}$, and $\mathbf{2 c}$ on inducible nitric oxide synthase (iNOS) and Cyclooxygenase 2 (COX-2) Cellular lysates were prepared from the with/without pretreatment tested compound $(5,10$, and $20 \mu \mathrm{M})$ for one hour and then with LPS $(1 \mu \mathrm{g} / \mathrm{mL})$ for $24 \mathrm{~h}$. Total cellular proteins were resolved by sodium dodecyl sulphate-polyacrylamide gel electrophoresis (SDS-PAGE), transferred to Polyvinylidene fluoride (PVDF) membranes, and detected with specific iNOS and COX-2 antibodies. $\beta$-actin was used as an internal control.

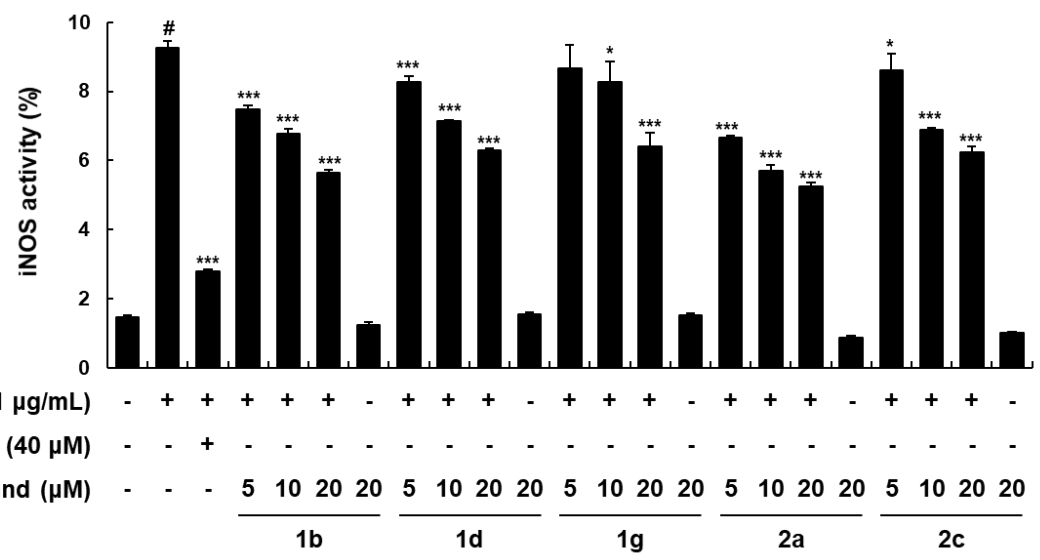

Figure 4. Effect of compounds $\mathbf{1 b}, \mathbf{1 d}, \mathbf{1 g}, \mathbf{2 a}$, and $\mathbf{2 c}$ on iNOS activity. Following pretreatment with lipopolysaccharide (LPS, $1 \mu \mathrm{g} / \mathrm{mL}$ ) for $12 \mathrm{~h}$ and wash with phosphate buffer solution (PBS), cells were treated with $1 \mathrm{~g}(5,10$, or $20 \mu \mathrm{M})$ for $12 \mathrm{~h} \mathrm{~N}^{6}$-(1-Iminoethyl)-L-lysine. (L-NIL) $(40 \mu \mathrm{M})$ was used as the positive control in the assay. Levels of NO in culture media were quantified using the Griess reaction assay. Data are presented as the means \pm SD of three independent experiments. $\# p<0.05$ versus the control cells; ${ }^{* * *} p<0.001$ versus LPS-stimulated cells; ${ }^{*}$ statistical significances were compared using ANOVA and Dunnett's post hoc test. 


\section{Materials and Methods}

\subsection{General}

All chemicals were commercially available and used with no further purification. The final compounds and intermediates were purified by column chromatography using silica gel (0.040-0.063 mm, 230-400 mesh) and technical grade solvents. Analytical thin layer chromatography (TLC) was adopted on silica gel $60 \mathrm{~F}_{254}$ plates from Merck (Merck, Massachusetts, MA, USA). Purity percentages of the target compounds were confirmed to be more than $96 \%$ by liquid chromatography-mass spectrometry (LC-MS). Proton nuclear magnetic resonance $\left({ }^{1} \mathrm{H}-\mathrm{NMR}\right)$ and carbon NMR $\left({ }^{13} \mathrm{C}-\mathrm{NMR}\right)$ spectra were recorded on a Bruker Avance 400 or 300 spectrometer (Massachusetts, MA, USA) using tetramethylsilane as an internal standard and signals are described as s (singlet), d (doublet), $\mathrm{t}$ (triplet), q (quartet), p (pentet), m (multiplet), brs (broad singlet), or dd (doublet of doublets). LC-MS analysis was carried out using the following system: Waters 2998 photodiode array detector, Waters 3100 mass detector, Waters SFO system fluidics organizer, Waters 2545 binary gradient module, Waters reagent manager, Waters 2767 sample manager, Waters 2998 photodiode and Sunfire ${ }^{\mathrm{TM}} \mathrm{C} 18$ column $(4.6 \times 50 \mathrm{~mm}, 5 \mu \mathrm{m}$ particle size) (Waters, Massachusetts, MA, USA). The solvent gradient $=95 \% \mathrm{~A}$ at $0 \mathrm{~min}, 1 \% \mathrm{~A}$ at $5 \mathrm{~min}$. Solvent $\mathrm{A}$ was $0.035 \%$ trifluoroacetic acid (TFA) in water, solvent $\mathrm{B}$ was $0.035 \%$ TFA in $\mathrm{CH}_{3} \mathrm{OH}$, and the flow rate was $3.0 \mathrm{~mL} / \mathrm{min}$. The area under the curve (AUC) was calculated using Waters MassLynx 4.1 Waters, Massachusetts, MA, USA) software. Solvents and liquid reagents were transferred using hypodermic syringes. Melting points were obtained on a Walden Precision Apparatus Electro thermal 9300 apparatus (Stone, Staffordshire, England) and were uncorrected.

3.2. Synthesis of N-(2-aminoethyl)benzenesulfonamide (8a), $N$-(2-aminoethyl)substituted benzenesulfonamides $(\mathbf{8 b}-\mathbf{i}), N$-(3-aminopropyl)benzenesulfonamide (9a), and $N$-(3-aminopropyl)benzenesulfonamides $(\mathbf{9 b}-\mathbf{i})$.

These compounds were synthesized performing the six-step procedure reported in the literature [42].

\subsection{Synthesis of 2-bromo-4-(3-(3-methoxyphenyl)-1-phenyl-1H-pyrazol-4-yl)pyridine (5)}

This compound was synthesized performing the four-step procedure reported in the literature [40].

3.4. Synthesis of $N^{1}$-(4-(3-(3-Methoxyphenyl)-1-phenyl-1H-pyrazol-4-yl)pyridin-2-yl)ethane1,2-diamine (6) and $N^{1}$-(4-(3-(3-Methoxyphenyl)-1-phenyl-1H-pyrazol-4-yl)pyridin-2-yl) propane-1,3-diamine (7)

These compounds were synthesized utilizing the five-step procedure reported in the literature [43]. The detailed procedures are mentioned in the supplementary file.

3.5. General Procedure for Synthesis of the Target Compounds N-(2-((4-(3-(3-methoxyphenyl)-1-phenyl-1Hpyrazol-4-yl)pyridin-2-yl)amino)ethyl)arylsulfonamides (1a-i) and N-(3-((4-(3-(3-methoxyphenyl)-1-phenyl1 H-pyrazol-4-yl)pyridin-2-yl)amino)propyl)arylsulfonamides (2a-i).

\subsubsection{Method A}

To a solution of compound 6 or $7(0.2 \mathrm{mmol})$ in anhydrous dichloromethane $(5 \mathrm{~mL})$, triethylamine $(50.5 \mathrm{mg}, 0.5 \mathrm{mmol})$ was added at $0{ }^{\circ} \mathrm{C}$. A solution appropriate arylsulfonyl chloride $(0.21 \mathrm{mmol})$ in anhydrous dichloromethane $(1 \mathrm{~mL})$ was added dropwise. The reaction mixture was stirred at room temperature for $24 \mathrm{~h}$. When the reaction was finished, the solvent was removed in vacuo, and the residue was partitioned between ethyl acetate $(5 \mathrm{~mL})$ and water $(5 \mathrm{~mL})$. The organic layer was separated and the aqueous layer was extracted with ethyl acetate $(3 \times 10 \mathrm{~mL})$. The combined organic layer was washed with saturated saline $(2 \times 5 \mathrm{~mL})$ and the organic solvent was evaporated under 
reduced pressure. The residue was purified by column chromatography (silica gel, hexane-ethyl acetate $4: 1 v / v$ ) to produce the required product.

\subsubsection{Method B}

A mixture of compound $5(81 \mathrm{mg}, 0.2 \mathrm{mmol})$ and compound 8 or $9(0.2 \mathrm{mmol})$ in pyridine was heated at $100{ }^{\circ} \mathrm{C}$ for $24 \mathrm{~h}$. After complete reaction, monitored by thin-layer chromatograph (TLC), pyridine was removed under reduced pressure. The residue was partitioned between water $(50 \mathrm{~mL})$ and ethylacetate $(50 \mathrm{~mL})$. The organic layer was separated and washed three times with distilled water $(3 \times 50 \mathrm{~mL})$ and dried over $\mathrm{Na}_{2} \mathrm{SO}_{4}$. The organic layer was evaporated and the residue was purified using column chromatography.

N-(2-((4-(3-(3-Methoxyphenyl)-1-phenyl-1H-pyrazol-4-yl)pyridin-2-yl)amino)ethyl)benzenesulfonamide (1a); White solid (65\%); mp 104-106 ${ }^{\circ} \mathrm{C} ;{ }^{1} \mathrm{H}-\mathrm{NMR}\left(300 \mathrm{MHz}, \mathrm{CDCl}_{3}\right) \delta 7.93$ (s, 1H, Ar-H), 7.86-7.79 (m, 4H, Ar-H), 7.51-7.40 (m, 3H, Ar-H), 7.25-7.21 (m, 5H, Ar-H), 6.92-6.88 (m, 1H, Ar-H), 6.77 (d, $J=9.0 \mathrm{~Hz}, 1 \mathrm{H}, \mathrm{Ar}-\mathrm{H}), 6.70(\mathrm{~s}, 1 \mathrm{H}, \mathrm{Ar}-\mathrm{H}), 6.42(\mathrm{~d}, J=6.0 \mathrm{~Hz}, 1 \mathrm{H}, \mathrm{Ar}-\mathrm{H}), 6.24(\mathrm{~s}, 1 \mathrm{H}, \mathrm{Ar}-\mathrm{H}), 4.98$ (brs, $1 \mathrm{H}$, $\mathrm{NH}), 3.65\left(\mathrm{~s}, 3 \mathrm{H}, \mathrm{OCH}_{3}\right), 3.32\left(\mathrm{~d}, J=3.0 \mathrm{~Hz}, 2 \mathrm{H}, \mathrm{CH}_{2}\right), 3.09\left(\mathrm{~d}, J=6.0 \mathrm{~Hz}, 2 \mathrm{H}, \mathrm{CH}_{2}\right) ;{ }^{13} \mathrm{C}-\mathrm{NMR}(75$ $\left.\mathrm{MHz}, \mathrm{CDCl}_{3}\right) \delta 159.6,158.6,147.4,141.9,140.1,140.1,139.5,139.4,132.4,131.0,130.0,129.9,128.9,128.8$, 127.6, 126.9, 125.1, 122.7, 120.0, 115.8, 114.7, 112.4, $105.9(\mathrm{Ar}-\mathrm{C}), 55.3\left(\mathrm{OCH}_{3}\right), 43.9\left(\mathrm{CH}_{2}\right), 41.6\left(\mathrm{CH}_{2}\right)$; LC-MS $(m / z)$ calculated for $\mathrm{C}_{29} \mathrm{H}_{27} \mathrm{~N}_{5} \mathrm{O}_{3} \mathrm{~S}: 525.18$, found: $526.0(\mathrm{M}+1)^{+}$.

4-Bromo-N-(2-((4-(3-(3-methoxyphenyl)-1-phenyl-1H-pyrazol-4-yl)pyridin-2-yl)amino)ethyl) benzenesulfonamide (1b); White solid (61\%); mp 136-138 ${ }^{\circ} \mathrm{C} ;{ }^{1} \mathrm{H}-\mathrm{NMR}\left(300 \mathrm{MHz}, \mathrm{CDCl}_{3}\right) \delta$ $7.96(\mathrm{~s}, 1 \mathrm{H}, \mathrm{Ar}-\mathrm{H}), 7.89(\mathrm{~d}, J=6.0 \mathrm{~Hz}, 1 \mathrm{H}, \mathrm{Ar}-\mathrm{H}), 7.64(\mathrm{~d}, J=9 \mathrm{~Hz}, 2 \mathrm{H}, \mathrm{Ar}-\mathrm{H}), 7.58-7.55(\mathrm{~m}, 2 \mathrm{H}, \mathrm{Ar}-\mathrm{H})$, 7.31-7.28 (m, 6H, Ar-H), $6.93(\mathrm{~d}, J=6.0 \mathrm{~Hz}, 1 \mathrm{H}, \mathrm{Ar}-\mathrm{H}), 6.81(\mathrm{~d}, J=9.0 \mathrm{~Hz}, 1 \mathrm{H}, \mathrm{Ar}-\mathrm{H}), 6.72(\mathrm{~s}, 1 \mathrm{H}$, Ar-H), $6.48(\mathrm{~d}, J=6.0 \mathrm{~Hz}, 1 \mathrm{H}, \mathrm{Ar}-\mathrm{H}), 6.24(\mathrm{~s}, 1 \mathrm{H}, \mathrm{Ar}-\mathrm{H}), 4.81(\mathrm{brs}, 1 \mathrm{H}, \mathrm{NH}), 3.69\left(\mathrm{~s}, 3 \mathrm{H}, \mathrm{OCH}_{3}\right), 3.36$ (brs, 2H, $\mathrm{CH}_{2}$ ), 3.12 (brs, $\left.2 \mathrm{H}, \mathrm{CH}_{2}\right) ;{ }^{13} \mathrm{C}-\mathrm{NMR}\left(75 \mathrm{MHz}, \mathrm{CDCl}_{3}\right) \delta 159.7,158.5,147.2,142.2,140.2$, 139.5, 139.3, 139.2, 132.6, 132.6, 132.1, 131.0, 130.0, 128.8, 128.5, 127.6, 127.1, 125.1, 122.7, 119.8, 115.8, 114.8, 112.6, 106.1 (Ar-C), $55.3\left(\mathrm{OCH}_{3}\right), 44.4\left(\mathrm{NH}^{\left.-\mathrm{CH}_{2}\right)}\right), 41.6\left(\mathrm{CH}_{2}-\mathrm{NH}\right)$; LC-MS $(m / z)$ calculated for $\mathrm{C}_{29} \mathrm{H}_{26} \mathrm{BrN}_{5} \mathrm{O}_{3} \mathrm{~S}: 603.09$, found: $605.0(\mathrm{M}+2)^{+}$.

4-Chloro-N-(2-((4-(3-(3-methoxyphenyl)-1-phenyl-1H-pyrazol-4-yl)pyridin-2-yl)amino)ethyl) benzenesulfonamide (1c); White solid (60\%); mp 132-134 ${ }^{\circ} \mathrm{C} ;{ }^{1} \mathrm{H}-\mathrm{NMR}\left(300 \mathrm{MHz}, \mathrm{CDCl}_{3}\right) \delta 7.94$ (s, 1H, Ar-H), $7.85(\mathrm{~d}, J=6.0 \mathrm{~Hz}, 1 \mathrm{H}, \mathrm{Ar}-\mathrm{H}), 7.72-7.69(\mathrm{~m}, 2 \mathrm{H}, \mathrm{Ar}-\mathrm{H}), 7.54-7.51$ (m, 2H, Ar-H), 7.39-7.22 $(\mathrm{m}, 6 \mathrm{H}, \mathrm{Ar}-\mathrm{H}), 6.91(\mathrm{~d}, J=9.0 \mathrm{~Hz}, 1 \mathrm{H}, \mathrm{Ar}-\mathrm{H}), 6.78(\mathrm{~d}, J=9.0 \mathrm{~Hz}, 1 \mathrm{H}, \mathrm{Ar}-\mathrm{H}), 6.70(\mathrm{~s}, 1 \mathrm{H}, \mathrm{Ar}-\mathrm{H}), 6.43(\mathrm{~d}$, $J=3.0 \mathrm{~Hz}, 1 \mathrm{H}, \mathrm{Ar}-\mathrm{H}), 6.24(\mathrm{~s}, 1 \mathrm{H}, \mathrm{Ar}-\mathrm{H}), 4.95(\mathrm{brs}, 1 \mathrm{H}, \mathrm{NH}), 3.66\left(\mathrm{~s}, 3 \mathrm{H}, \mathrm{OCH}_{3}\right), 3.33(\mathrm{~d}, J=3.0 \mathrm{~Hz}, 2 \mathrm{H}$, $\left.\mathrm{NH}-\mathrm{CH}_{2}\right), 3.09\left(\mathrm{~d}, J=3.0 \mathrm{~Hz}, 2 \mathrm{H},-\mathrm{CH}_{2}-\mathrm{NH}\right) ;{ }^{13} \mathrm{C}-\mathrm{NMR}\left(75 \mathrm{MHz}, \mathrm{CDCl}_{3}\right) \delta 159.6,158.5,147.3,142.0$, 140.1, 139.5, 139.3, 138.6, 131.0, 129.9, 129.1, 128.8, 127.6, 125.1, 122.7, 119.9, 115.8, 114.7, 112.5, 106.9 (Ar-C), $55.2\left(\mathrm{OCH}_{3}\right), 44.1\left(\mathrm{NH}-\mathrm{CH}_{2}\right), 41.5\left(-\mathrm{CH}_{2}-\mathrm{NH}\right)$.; LC-MS $(\mathrm{m} / z)$ calculated for $\mathrm{C}_{29} \mathrm{H}_{26} \mathrm{ClN}_{5} \mathrm{O}_{3} \mathrm{~S}$ : 559.14, found: $560.0(\mathrm{M}+1)^{+}$.

4-Fluoro-N-(2-((4-(3-(3-methoxyphenyl)-1-phenyl-1H-pyrazol-4-yl)pyridin-2-yl)amino)ethyl) benzenesulfonamide (1d); White solid (67\%); mp 155-156 ${ }^{\circ} \mathrm{C} ;{ }^{1} \mathrm{H}-\mathrm{NMR}\left(400 \mathrm{MHz}, \mathrm{CDCl}_{3}\right) \delta$ 7.83 (s, 1H, Ar-H), 7.71-7.67 (m, 3H, Ar-H), 7.19-7.15 (m, 5H, Ar-H), 6.99 (t, J = 8.4 Hz, 2H, Ar-H), $6.80(\mathrm{~d}, J=8.4 \mathrm{~Hz}, 1 \mathrm{H}, \mathrm{Ar}-\mathrm{H}), 6.67(\mathrm{~d}, J=8.8 \mathrm{~Hz}, 1 \mathrm{H}$, ar- $\mathrm{H}), 6.59(\mathrm{~s}, 1 \mathrm{H}, \mathrm{Ar}-\mathrm{H}), 6.34(\mathrm{~d}, J=5.2 \mathrm{~Hz}, 1 \mathrm{H}$, Ar-H), 6.13 (s, 1H, Ar-H), 4.85 (brs, NH), $3.56\left(\mathrm{~s}, 3 \mathrm{H}, \mathrm{OCH}_{3}\right), 3.23\left(\mathrm{~s}, 2 \mathrm{H}, \mathrm{NH}-\mathrm{CH}_{2}\right), 2.98$ (d, J = 4.4 $\left.\mathrm{Hz}, 2 \mathrm{H},-\mathrm{CH}_{2}-\mathrm{NH}\right) ;{ }^{13} \mathrm{C}-\mathrm{NMR}\left(100 \mathrm{MHz}, \mathrm{CDCl}_{3}\right) \delta 159.7,158.6,147.1,142.2,140.1,139.5,139.3,136.1$, 130.9, 130.0, 129.7, 129.6, 129.5, 128.9, 128.7, 125.2, 125.0, 122.7, 119.8, 116.0, 115.0, 112.5, 105.9 (Ar-C), $55.3\left(\mathrm{OCH}_{3}\right), 44.2\left(\mathrm{CH}_{2}\right), 41.6\left(\mathrm{CH}_{2}\right)$; LC-MS $(\mathrm{m} / z)$ calculated for $\mathrm{C}_{29} \mathrm{H}_{26} \mathrm{FN}_{5} \mathrm{O}_{3} \mathrm{~S}: 543.17$, found: 544.0 $(\mathrm{M}+1)^{+}$.

4-Methoxy-N-(2-((4-(3-(3-methoxyphenyl)-1-phenyl-1H-pyrazol-4-yl)pyridin-2-yl)amino)ethyl) benzenesulfonamide (1e); White solid (62\%); mp 144-146 ${ }^{\circ} \mathrm{C} ;{ }^{1} \mathrm{H}-\mathrm{NMR}\left(400 \mathrm{MHz}, \mathrm{CDCl}_{3}\right) \delta 7.94(\mathrm{~s}, 1 \mathrm{H}$, Ar-H), $7.88(\mathrm{~d}, J=4.0 \mathrm{~Hz}, 1 \mathrm{H}, \mathrm{Ar}-\mathrm{H}), 7.74(\mathrm{~d}, J=8.0 \mathrm{~Hz}, 2 \mathrm{H}, \mathrm{Ar}-\mathrm{H}), 7.33-7.23(\mathrm{~m}, 6 \mathrm{H}, \mathrm{Ar}-\mathrm{H}), 6.91(\mathrm{~d}$, $J=8.0 \mathrm{~Hz}, 3 \mathrm{H}, \mathrm{Ar}-\mathrm{H}), 6.79-6.77(\mathrm{~m}, 1 \mathrm{H}, \mathrm{Ar}-\mathrm{H}), 6.70-6.69(\mathrm{~m}, 1 \mathrm{H}, \mathrm{Ar}-\mathrm{H}), 6.43(\mathrm{dd}, J=8.0, J=4.0 \mathrm{~Hz}, 1 \mathrm{H}$, Ar-H), $6.23(\mathrm{~s}, 1 \mathrm{H}, \mathrm{Ar}-\mathrm{H}), 4.85(\mathrm{~s}, \mathrm{NH}), 3.83\left(\mathrm{~s}, 3 \mathrm{H}, \mathrm{OCH}_{3}\right), 3.67\left(\mathrm{~s}, 3 \mathrm{H}, \mathrm{OCH}_{3}\right), 3.34(\mathrm{t}, J=8.0 \mathrm{~Hz}, 2 \mathrm{H}$, 
$\left.\mathrm{NH}-\mathrm{CH}_{2}-\right), 3.08\left(\mathrm{t}, J=8.0 \mathrm{~Hz}, 2 \mathrm{H},-\mathrm{CH}_{2}-\mathrm{NH}\right) ;{ }^{13} \mathrm{C}-\mathrm{NMR}\left(100 \mathrm{MHz}, \mathrm{CDCl}_{3}\right) \delta$ 162.6, 159.6, 158.6, 147.5, $141.9,140.1,139.5,139.4,131.6,131.0,129.9,129.1,128.8,127.6,125.1,122.7,120.0,115.7,114.7,114.1$, 112.4, 105.9 (Ar-C), $55.5\left(\mathrm{OCH}_{3}\right), 55.3\left(\mathrm{OCH}_{3}\right), 43.8\left(\mathrm{CH}_{2}\right), 41.5\left(\mathrm{CH}_{2}\right)$; LC-MS $(m / z)$ calculated for $\mathrm{C}_{30} \mathrm{H}_{29} \mathrm{~N}_{5} \mathrm{O}_{4} \mathrm{~S}: 555.19$, found: $556.0(\mathrm{M}+1)^{+}$.

N-(2-((4-(3-(3-Methoxyphenyl)-1-phenyl-1H-pyrazol-4-yl)pyridin-2-yl)amino)ethyl)-4-methyl benzenesulfonamide (1f); White solid (69\%); mp 150-152 ${ }^{\circ} \mathrm{C} ;{ }^{1} \mathrm{H}-\mathrm{NMR}\left(300 \mathrm{MHz}, \mathrm{CDCl}_{3}\right) \delta 7.97$ $(\mathrm{s}, 1 \mathrm{H}, \mathrm{Ar}-\mathrm{H}), 7.91(\mathrm{~d}, J=6.0 \mathrm{~Hz}, 1 \mathrm{H}), 7.71(\mathrm{~d}, J=9.0 \mathrm{~Hz}, 2 \mathrm{H}, \mathrm{Ar}-\mathrm{H}), 7.32-7.26(\mathrm{~m}, 7 \mathrm{H}), 6.94(\mathrm{~d}$, $J=9.0 \mathrm{~Hz}, 1 \mathrm{H}, \mathrm{Ar}-\mathrm{H}), 6.81(\mathrm{~d}, J=6.0 \mathrm{~Hz}, 1 \mathrm{H}, \mathrm{Ar}-\mathrm{H}), 6.72(\mathrm{~s}, 1 \mathrm{H}, \mathrm{Ar}-\mathrm{H}), 6.49(\mathrm{~d}, J=3.0 \mathrm{~Hz}, 1 \mathrm{H}, \mathrm{Ar}-\mathrm{H})$, $6.26(\mathrm{~s}, 1 \mathrm{H}, \mathrm{Ar}-\mathrm{H}), 4.97$ (brs, 1H, NH), $3.70\left(\mathrm{~s}, 3 \mathrm{H}, \mathrm{OCH}_{3}\right), 3.36\left(\mathrm{brs}, 2 \mathrm{H}, \mathrm{NH}-\mathrm{CH}_{2}-\right), 3.12(\mathrm{t}, J=6.0 \mathrm{~Hz}$, $\left.2 \mathrm{H},-\mathrm{CH}_{2}-\mathrm{NH}\right), 2.43\left(\mathrm{~s}, 3 \mathrm{H}, \mathrm{CH}_{3}\right) ;{ }^{13} \mathrm{C}-\mathrm{NMR}\left(75 \mathrm{MHz} \mathrm{CDCl}_{3}\right) \delta 159.7,158.5,147.4,143.1,142.1,140.1$, 139.6, 139.3, 137.1, 131.1, 129.9, 129.5, 128.8, 127.6, 127.0, 125.1, 122.7, 120.0, 115.7, 114.7, 112., 105.5 (Ar-C), $55.3(\mathrm{OCH} 3), 44.0\left(\mathrm{CH}_{2}\right), 41.7\left(\mathrm{CH}_{2}\right), 21.4\left(\mathrm{CH}_{3}\right)$; LC-MS $(\mathrm{m} / z)$ calculated for $\mathrm{C}_{30} \mathrm{H}_{29} \mathrm{~N}_{5} \mathrm{O}_{3} \mathrm{~S}$ : 539.20, found: $540.0(\mathrm{M}+1)^{+}$.

N-(2-((4-(3-(3-Methoxyphenyl)-1-phenyl-1H-pyrazol-4-yl)pyridin-2-yl)amino)ethyl)-4-(trifluoromethyl) benzenesulfonamide (1g); White solid (74\%); mp 132-134 ${ }^{\circ} \mathrm{C} ;{ }^{1} \mathrm{H}-\mathrm{NMR}\left(300 \mathrm{MHz}, \mathrm{CDCl}_{3}\right) \delta 7.91(\mathrm{~d}$, $J=9.0 \mathrm{~Hz}, 4 \mathrm{H}, \mathrm{Ar}-\mathrm{H}), 7.71$ (s, 1H, Ar-H), 7.30 (brs, 6H, Ar-H), 6.93 (s, 1H, Ar-H), 6.80 (s, 1H, Ar-H), $6.71(\mathrm{~s}, 2 \mathrm{H}, \mathrm{Ar}-\mathrm{H}), 6.48(\mathrm{~s}, 1 \mathrm{H}, \mathrm{Ar}-\mathrm{H}), 6.25(\mathrm{~s}, 1 \mathrm{H}, \mathrm{Ar}-\mathrm{H}), 4.87$ (brs, $1 \mathrm{H}, \mathrm{NH}), 3.67\left(\mathrm{~s}, 3 \mathrm{H}, \mathrm{OCH}_{3}\right), 3.37$ (s, 2H, NH-CH $2-), 3.14\left(\mathrm{~s}, 2 \mathrm{H},-\mathrm{CH}_{2}-\mathrm{NHSO}_{2}\right) ;{ }^{13} \mathrm{C}-\mathrm{NMR}\left(75 \mathrm{MHz}, \mathrm{CDCl}_{3}\right) \delta$ 159.7, 158.5, 147.1, 147.0, 143.8, 142.4, 139.5, 139.4, 139.2, 134.1, 133.7, 130.9, 130.1, 129.9, 128.9, 127.4, 126.0, 125.2, 125.0, 122.7, 119.7, 115.8, 114.7, 112.8, 106.2 (Ar-C), $55.3\left(\mathrm{OCH}_{3}\right), 44.7\left(\mathrm{CH}_{2}\right), 41.7\left(\mathrm{CH}_{2}\right)$; LC-MS $(m / z)$ calculated for $\mathrm{C}_{30} \mathrm{H}_{26} \mathrm{~F}_{3} \mathrm{~N}_{5} \mathrm{O}_{3} \mathrm{~S}: 593.17$, found: $594.0(\mathrm{M}+1)^{+}$.

3-Fluoro-N-(2-((4-(3-(3-methoxyphenyl)-1-phenyl-1H-pyrazol-4-yl)pyridin-2-yl)amino)ethyl) benzenesulfonamide (1h); White solid (66\%); mp $118-120{ }^{\circ} \mathrm{C} ;{ }^{1} \mathrm{H}-\mathrm{NMR}\left(300 \mathrm{MHz}, \mathrm{CDCl}_{3}\right) \delta$ $7.94(\mathrm{~s}, 1 \mathrm{H}, \mathrm{Ar}-\mathrm{H}), 7.85(\mathrm{~d}, J=6.0 \mathrm{~Hz}, 1 \mathrm{H}, \mathrm{Ar}-\mathrm{H}), 7.59(\mathrm{~s}, 1 \mathrm{H}, \mathrm{Ar}-\mathrm{H}), 7.49(\mathrm{~s}, 1 \mathrm{H}, \mathrm{Ar}-\mathrm{H}), 7.46-7.37(\mathrm{~m}$, 2H, Ar-H), 7.29-7.21 (m, $6 \mathrm{H}), 6.90(\mathrm{~d}, J=9.0 \mathrm{~Hz}, 1 \mathrm{H}, \mathrm{Ar}-\mathrm{H}), 6.78(\mathrm{~d}, J=9.0 \mathrm{~Hz}, 1 \mathrm{H}, \mathrm{Ar}-\mathrm{H}), 6.71(\mathrm{~s}$, $1 \mathrm{H}), 6.43(\mathrm{~d}, J=6.0 \mathrm{~Hz}, 1 \mathrm{H}, \mathrm{Ar}-\mathrm{H}), 6.25(\mathrm{~s}, 1 \mathrm{H}, \mathrm{Ar}-\mathrm{H}), 4.99$ (brs, $1 \mathrm{H}, \mathrm{NH}), 3.65\left(\mathrm{~s}, 3 \mathrm{H}, \mathrm{OCH}_{3}\right), 3.33$ (brs, $\left.2 \mathrm{H}, \mathrm{NH}-\mathrm{CH}_{2}-\right), 3.10\left(\mathrm{t}, J=6.0 \mathrm{~Hz}, 2 \mathrm{H},-\mathrm{CH}_{2}-\mathrm{NH}-\mathrm{SO}_{2}\right) ;{ }^{13} \mathrm{C}-\mathrm{NMR}\left(75 \mathrm{MHz}, \mathrm{CDCl}_{3}\right) \delta$ 159.6, 158.6, 147.3, 142.2, 142.0, 140.2, 139.5, 139.4, 130.9, 130.8, 130.7, 129.9, 128.8, 127.6, 125.1, 122.7, 119.9, 119.6, 119.3, 115.7, 114.7, 114.4, 114.1, 112.5, 106.0 (Ar-C), $55.2\left(\mathrm{OCH}_{3}\right), 44.2\left(\mathrm{CH}_{2}\right), 41.5\left(\mathrm{CH}_{2}\right) ; \mathrm{LC}-\mathrm{MS}(\mathrm{m} / \mathrm{z})$ calculated for $\mathrm{C}_{29} \mathrm{H}_{26} \mathrm{FN}_{5} \mathrm{O}_{3} \mathrm{~S}: 543.17$, found: $544.0(\mathrm{M}+1)^{+}$.

N-(2-((4-(3-(3-Methoxyphenyl)-1-phenyl-1H-pyrazol-4-yl)pyridin-2-yl)amino)ethyl)naphthalene-1sulfonamide (1i); White solid (71\%); mp 178-180 ${ }^{\circ} \mathrm{C} ;{ }^{1} \mathrm{H}-\mathrm{NMR}\left(400 \mathrm{MHz}, \mathrm{CDCl}_{3}\right) \delta 8.38(\mathrm{~s}, 1 \mathrm{H}, \mathrm{Ar}-\mathrm{H})$, 7.91-7.85 (m, 4H, Ar-H), 7.75 (dd, J = 8.8 Hz, J = 1.6 Hz, 1H, Ar-H), 7.64-7.55 (m, 2H, Ar-H), 7.34-7.21 $(\mathrm{m}, 6 \mathrm{H}, \mathrm{Ar}-\mathrm{H}), 7.02(\mathrm{brs}, 1 \mathrm{H}, \mathrm{NH}), 6.89(\mathrm{dd}, J=8.4 \mathrm{~Hz}, J=2.0 \mathrm{~Hz}, 1 \mathrm{H}, \mathrm{Ar}-\mathrm{H}), 6.76(\mathrm{~d}, J=7.6 \mathrm{~Hz}, 1 \mathrm{H}$, Ar-H), $6.68(\mathrm{~s}, 1 \mathrm{H}, \mathrm{Ar}-\mathrm{H}), 6.42(\mathrm{~d}, J=4.8 \mathrm{~Hz}, 1 \mathrm{H}, \mathrm{Ar}-\mathrm{H}), 6.17(\mathrm{~s}, 1 \mathrm{H}, \mathrm{Ar}-\mathrm{H}), 4.87$ (brs, 1H, NH), 3.65 (s, $\left.3 \mathrm{H}, \mathrm{OCH}_{3}\right), 3.34\left(\mathrm{~d}, J=4.4 \mathrm{~Hz}, 2 \mathrm{H}, \mathrm{NH}-\mathrm{CH}_{2}-\right), 3.14\left(\mathrm{t}, J=5.2 \mathrm{~Hz}, 2 \mathrm{H},-\mathrm{CH}_{2}-\mathrm{NH}-\mathrm{SO}_{2}\right) ;{ }^{13} \mathrm{C}-\mathrm{NMR}(100$ $\left.\mathrm{MHz}, \mathrm{CDCl}_{3}\right) \delta 159.6,158.4,147.1,142.1,140.1,139.5,139.4,136.8,134.6,132.1,130.9,129.8,129.3,129.1$, 128.8, 128.6, 128.2, 127.8, 127.6, 127.4, 125.1, 122.7, 122.3, 119.9, 115.7, 114.7, 112.4, 105.9 (Ar-C), 55.2 $\left(\mathrm{OCH}_{3}\right), 44.3\left(\mathrm{CH}_{2}\right), 41.5\left(\mathrm{CH}_{2}\right)$; LC-MS $(\mathrm{m} / z)$ calculated for $\mathrm{C}_{33} \mathrm{H}_{29} \mathrm{~N}_{5} \mathrm{O}_{3} \mathrm{~S}: 575.20$, found: $576.0(\mathrm{M}+$ $1)^{+}$.

N-(3-((4-(3-(3-Methoxyphenyl)-1-phenyl-1H-pyrazol-4-yl)pyridin-2-yl)amino)propyl)

benzenesulfonamide (2a); White solid (60\%); mp $119-120{ }^{\circ} \mathrm{C} ;{ }^{1} \mathrm{H}-\mathrm{NMR}\left(300 \mathrm{MHz}, \mathrm{CDCl}_{3}\right) \delta$ $7.98(\mathrm{~d}, J=12.0 \mathrm{~Hz}, 2 \mathrm{H}, \mathrm{Ar}-\mathrm{H}), 7.83(\mathrm{~d}, J=9.0 \mathrm{~Hz}, 2 \mathrm{H}, \mathrm{Ar}-\mathrm{H}), 7.52-7.45$ (m, 3H, Ar-H), 7.31-7.24 $(\mathrm{m}, 6 \mathrm{H}, \mathrm{Ar}-\mathrm{H}), 6.93(\mathrm{~d}, J=6.0 \mathrm{~Hz}, 1 \mathrm{H}, \mathrm{Ar}-\mathrm{H}), 6.79(\mathrm{~d}, J=9.0 \mathrm{~Hz}, 1 \mathrm{H}, \mathrm{Ar}-\mathrm{H}), 6.71(\mathrm{~s}, 1 \mathrm{H}, \mathrm{Ar}-\mathrm{H}), 6.45$ $(\mathrm{d}, J=3.0 \mathrm{~Hz}, 1 \mathrm{H}, \mathrm{Ar}-\mathrm{H}), 6.22(\mathrm{~s}, 1 \mathrm{H}, \mathrm{Ar}-\mathrm{H}), 4.73$ (brs, 1H, NH), 3.68 (s, 3H, OCH 3 ), 3.31 (brs, $2 \mathrm{H}$, NH-CH $\left.2^{-}\right), 2.97$ (brs, $\left.2 \mathrm{H},-\mathrm{CH}_{2}-\mathrm{NH}-\mathrm{SO}_{2}\right), 1.67-1.58\left(\mathrm{~m}, 2 \mathrm{H},-\mathrm{CH}_{2}-\right)$; ${ }^{13} \mathrm{C}-\mathrm{NMR}\left(75 \mathrm{MHz}, \mathrm{CDCl}_{3}\right) \delta 159.6$, 158.7, 147.2, 142.1, 140.4, 140.1, 139.5, 139.3, 132.2, 131.0, 129.9, 128.9, 128.8, 127.6, 126.9, 125.1, 122.7, 120.0, 115.7, 114.8, 112.1, 105.7 (Ar-C), $55.3\left(\mathrm{OCH}_{3}\right), 40.1\left(\mathrm{CH}_{2}\right), 38.3\left(\mathrm{CH}_{2}\right), 29.9\left(\mathrm{CH}_{2}\right)$; LC-MS $(\mathrm{m} / \mathrm{z})$ calculated for $\mathrm{C}_{30} \mathrm{H}_{29} \mathrm{~N}_{5} \mathrm{O}_{3} \mathrm{~S}: 539.20$, found: $540.0(\mathrm{M}+1)^{+}$. 
4-Bromo-N-(3-((4-(3-(3-methoxyphenyl)-1-phenyl-1H-pyrazol-4-yl)pyridin-2-yl)amino) propyl) benzenesulfonamide (2b); White solid (62\%); mp 117-119 ${ }^{\circ} \mathrm{C} ;{ }^{1} \mathrm{H}-\mathrm{NMR}\left(400 \mathrm{MHz}, \mathrm{CDCl}_{3}\right) \delta 7.98(\mathrm{~s}, 1 \mathrm{H}$, Ar-H), 7.90 (d, J = 5.6 Hz, 1H, Ar-H), 7.69 (d, J = 8.8 Hz, 2H, Ar-H), 7.60 (d, J = 8.8 Hz, 2H, Ar-H), 7.35-7.20 (m, 6H, Ar-H), $6.95(\mathrm{dd}, J=8.0, J=2.0 \mathrm{~Hz}, 1 \mathrm{H}, \mathrm{Ar}-\mathrm{H}), 6.72(\mathrm{t}, J=2.0 \mathrm{~Hz}, 1 \mathrm{H}, \mathrm{Ar}-\mathrm{H}), 6.49$ $(\mathrm{dd}, J=6.0 \mathrm{~Hz}, J=1.6 \mathrm{~Hz}, 1 \mathrm{H}, \mathrm{Ar}-\mathrm{H}), 6.28$ (s, 1H, Ar-H), 5.21 (brs, 1H, NH), 3.70 (s, 3H, OCH $\mathrm{O}_{3}$, $3.36\left(\mathrm{q}, J=6.4 \mathrm{~Hz}, 2 \mathrm{H}, \mathrm{NH}-\mathrm{CH}_{2}-\right), 2.99\left(\mathrm{~d}, J=5.6 \mathrm{~Hz}, 2 \mathrm{H},-\mathrm{CH}_{2} \mathrm{NHSO}_{2}\right), 1.68(\mathrm{p}, J=6.4 \mathrm{~Hz}, 2 \mathrm{H}$, $\left.\mathrm{CH}_{2}-\mathrm{CH}_{2}-\mathrm{CH}_{2}\right) ;{ }^{13} \mathrm{C}-\mathrm{NMR}\left(\overline{75} \mathrm{MHz}, \mathrm{CDCl}_{3}\right) \delta 159.7,158.9, \overline{147.3}, 142.1,140.2,139.6,139.4,132.2$, 131.0, 130.0, 128.8, 128.5, 127.6, 127.1, 125.1, 122.8, 120.0, 115.8, 114.8, 112.1, 105.9 (Ar-C), $55.3\left(\mathrm{OCH}_{3}\right)$, $40.2\left(\mathrm{CH}_{2}\right), 38.3\left(\mathrm{CH}_{2}\right), 29.9\left(\mathrm{CH}_{2}\right)$; LC-MS $(\mathrm{m} / z)$ calculated for $\mathrm{C}_{30} \mathrm{H}_{28} \mathrm{BrN}_{5} \mathrm{O}_{3} \mathrm{~S}: 617.11$, found: 618.00 $(\mathrm{M}+1)^{+}$.

4-Chloro-N-(3-((4-(3-(3-methoxyphenyl)-1-phenyl-1H-pyrazol-4-yl)pyridin-2-yl)amino) propyl) benzenesulfonamide (2c); White solid (62\%); mp 98-100 ${ }^{\circ} \mathrm{C} ;{ }^{1} \mathrm{H}-\mathrm{NMR}\left(400 \mathrm{MHz}, \mathrm{CDCl}_{3}\right) \delta 7.95(\mathrm{~s}, 1 \mathrm{H}$, Ar-H), $7.93(\mathrm{~d}, J=5.2 \mathrm{~Hz}, 1 \mathrm{H}, \mathrm{Ar}-\mathrm{H}), 7.75(\mathrm{~d}, J=8.4 \mathrm{~Hz}, 2 \mathrm{H}, \mathrm{Ar}-\mathrm{H}), 7.42$ (d, J = 8.4 Hz, 2H, Ar-H), 7.32-7.25 (m, 6H, Ar-H), $6.93(\mathrm{dd}, J=8.0 \mathrm{~Hz}, J=2.0 \mathrm{~Hz}, 1 \mathrm{H}, \mathrm{Ar}-\mathrm{H}), 6.79$ (d, J = $7.6 \mathrm{~Hz}, 1 \mathrm{H}, \mathrm{Ar}-\mathrm{H}), 6.71$ (s, 1H, Ar-H), 6.45 (d, J = 5.6 Hz, 1H, Ar-H), 6.25 (s, 1H, Ar-H), 4.84 (brs, 1H, NH), $3.68\left(\mathrm{~s}, 3 \mathrm{H}, \mathrm{OCH}_{3}\right)$, $3.34\left(\mathrm{~d}, J=5.6 \mathrm{~Hz}, 2 \mathrm{H}, \mathrm{NH}-\mathrm{CH}_{2}-\right), 2.90\left(\mathrm{brs}, 2 \mathrm{H},-\mathrm{CH}_{2} \mathrm{NHSO}_{2}\right), 1.66\left(\mathrm{t}, J=6.0 \mathrm{~Hz}, 2 \mathrm{H},-\mathrm{CH}_{2}-\right) ;{ }^{13} \mathrm{C}-\mathrm{NMR}$ $\left(100 \mathrm{MHz}_{,} \mathrm{CDCl}_{3}\right) \delta 159.4, \overline{158.4}, 146.8,142.8,140.2,139.3,139.3,138.9,138.6,130.9,130.0,129.5,129.2$, 128.8, 128.4, 127.6, 125.1, 122.7, 119.8, 115.7, 114.8, 112.0, 105.9 (Ar-C), $55.2\left(\mathrm{OCH}_{3}\right), 40.0\left(\mathrm{CH}_{2}\right), 38.2$ $\left(\mathrm{CH}_{2}\right), 29.9\left(\mathrm{CH}_{2}\right)$; LC-MS $(m / z)$ calculated for $\mathrm{C}_{30} \mathrm{H}_{28} \mathrm{ClN}_{5} \mathrm{O}_{3} \mathrm{~S}: 573.16$, found: $574.0(\mathrm{M}+1)^{+}$.

4-Fluoro-N-(3-((4-(3-(3-methoxyphenyl)-1-phenyl-1H-pyrazol-4-yl)pyridin-2-yl)amino) propyl) benzenesulfonamide (2d); White solid (75\%); mp 92-94 ${ }^{\circ} \mathrm{C} ;{ }^{1} \mathrm{H}-\mathrm{NMR}\left(300 \mathrm{MHz}, \mathrm{CDCl}_{3}\right) \delta 7.96(\mathrm{~s}, 2 \mathrm{H}$, Ar-H), 7.82 (d, J = 3.0 Hz, 2H, Ar-H), 7.32-7.28 (m, 6H, Ar-H), 7.14 (t, J = 9.0 Hz, 2H, Ar-H), 6.94 $(\mathrm{d}, J=6.0 \mathrm{~Hz}, 1 \mathrm{H}, \mathrm{Ar}-\mathrm{H}), 6.80(\mathrm{~d}, J=6.0 \mathrm{~Hz}, 1 \mathrm{H}, \mathrm{Ar}-\mathrm{H}), 6.72(\mathrm{~s}, 1 \mathrm{H}, \mathrm{Ar}-\mathrm{H}), 6.46(\mathrm{~d}, J=6.0 \mathrm{~Hz}, 1 \mathrm{H}$, Ar-H), 6.24 (s, 1H, Ar-H), 4.60 (brs, 1H, NH), 3.69 (s, 3H, OCH $), 3.36$ (s, 2H, NH-CH2-), 2.98 (brs, $2 \mathrm{H}$, $\left.-\mathrm{CH}_{2} \mathrm{NHSO}_{2}\right), 1.66\left(\mathrm{~d}, J=6.0 \mathrm{~Hz}, 2 \mathrm{H},-\mathrm{CH}_{2}-\right) ;{ }^{13} \mathrm{C}-\mathrm{NMR}\left(75 \mathrm{MHz}, \mathrm{CDCl}_{3}\right) \delta$ 159.6, 158.7, 147.2, 140.1, $139.3,131.0,129.9,129.6,129.5,128.8,127.6,125.1,122.7,119.9,116.2,115.9,115.7,114.8,112.2,106.0$ $(\mathrm{Ar}-\mathrm{C}), 55.2\left(\mathrm{OCH}_{3}\right), 40.0\left(\mathrm{CH}_{2}\right), 38.2\left(\mathrm{CH}_{2}\right), 30.0\left(\mathrm{CH}_{2}\right)$; LC-MS $(\mathrm{m} / z)$ calculated for $\mathrm{C}_{30} \mathrm{H}_{28} \mathrm{FN}_{5} \mathrm{O}_{3} \mathrm{~S}$ : 557.19, found: $558.0(\mathrm{M}+1)^{+}$.

4-Methoxy-N-(3-((4-(3-(3-methoxyphenyl)-1-phenyl-1H-pyrazol-4-yl)pyridin-2-yl)amino) propyl) benzenesulfonamide (2e); White solid (71\%); mp 124-126 ${ }^{\circ} \mathrm{C} ;{ }^{1} \mathrm{H}-\mathrm{NMR}\left(300 \mathrm{MHz}, \mathrm{CDCl}_{3}\right) \delta 7.96(\mathrm{~s}, 1 \mathrm{H}$, Ar-H), 7.94 (d, J = 6.0 Hz, 1H, Ar-H), 7.76 (d, J = 9.0 Hz, 2H, Ar-H),7.33-7.24 (m, 6H, Ar-H), 6.93 (d, $J=9.0 \mathrm{~Hz}, 3 \mathrm{H}, \mathrm{Ar}-\mathrm{H}), 6.79$ (d, J=9.0 Hz, 1H, Ar-H), 6.71 (s, 1H, Ar-H), 6.54 (brs, 1H, NH), 6.45 (d, $J=3.0 \mathrm{~Hz}, 1 \mathrm{H}, \mathrm{Ar}-\mathrm{H}), 6.22(\mathrm{~s}, 1 \mathrm{H}, \mathrm{Ar}-\mathrm{H}), 4.61$ (brs, 1H, NH), $3.86\left(\mathrm{~s}, 3 \mathrm{H}, \mathrm{OCH}_{3}\right), 3.68\left(\mathrm{~s}, 3 \mathrm{H}, \mathrm{OCH}_{3}\right)$, $3.32\left(\mathrm{t}, J=6.0 \mathrm{~Hz}, 2 \mathrm{H}, \mathrm{NH}-\mathrm{CH}_{2}-\right), 2.96\left(\mathrm{t}, J=6.0 \mathrm{~Hz}, 2 \mathrm{H},-\mathrm{CH}_{2} \mathrm{NHSO}_{2}\right), 1.65\left(\mathrm{p}, J=6.0 \mathrm{~Hz}, 2 \mathrm{H},-\mathrm{CH}_{2}-\right)$; ${ }^{13} \mathrm{C}-\mathrm{NMR}\left(75 \mathrm{MHz}, \mathrm{CDCl}_{3}\right) \delta 159.7,158.8,147.5,142.0, \overline{140.1}, 139.6,139.4,132.0,131.1,130.0,128.8$, 127.6, 125.1, 122.8, 120.1, 115.7, 114.8, 114.1, 112.2, $105.7(\mathrm{Ar}-\mathrm{C}), 55.6\left(\mathrm{OCH}_{3}\right), 55.3\left(\mathrm{OCH}_{3}\right), 40.2\left(\mathrm{CH}_{2}\right)$, 38.4 $\left(\mathrm{CH}_{2}\right)$, $30.0\left(\mathrm{CH}_{2}\right)$; LC-MS $(m / z)$ calculated for $\mathrm{C}_{31} \mathrm{H}_{31} \mathrm{~N}_{5} \mathrm{O}_{3} \mathrm{~S}: 569.21$, found: $570.0(\mathrm{M}+1)^{+}$.

N-(3-((4-(3-(3-Methoxyphenyl)-1-phenyl-1H-pyrazol-4-yl)pyridin-2-yl)amino)propyl)-4methylbenzenesulfonamide (2f); Buff solid (72\%); mp 94-96 ${ }^{\circ} \mathrm{C} ;{ }^{1} \mathrm{H}-\mathrm{NMR}\left(300 \mathrm{MHz}, \mathrm{CDCl}_{3}\right) \delta$ 7.95 (s, 1H, Ar-H), 7.91 (d, $J=6.0 \mathrm{~Hz}, 1 \mathrm{H}, \mathrm{Ar}-\mathrm{H}), 7.71(\mathrm{~d}, J=9.0 \mathrm{~Hz}, 2 \mathrm{H}, \mathrm{Ar}-\mathrm{H}), 7.30-7.24(\mathrm{~m}, 7 \mathrm{H}, \mathrm{Ar}-\mathrm{H})$, $6.92(\mathrm{~d}, J=6.0 \mathrm{~Hz}, 1 \mathrm{H}, \mathrm{Ar}-\mathrm{H}), 6.79(\mathrm{~d}, J=6.0 \mathrm{~Hz}, 1 \mathrm{H}, \mathrm{Ar}-\mathrm{H}), 6.71(\mathrm{~s}, 1 \mathrm{H}, \mathrm{Ar}-\mathrm{H}), 6.44(\mathrm{~d}, J=6.0 \mathrm{~Hz}, 1 \mathrm{H}$, Ar-H), 6.23 (s, 1H, Ar-H), 4.78 (brs, 1H, NH), 3.67 (s, 3H, OCH $), 3.26$ (brs, 2H, NH-CH $\left.2^{-}\right), 2.94(\mathrm{~d}$, $\left.J=3.0 \mathrm{~Hz}, 2 \mathrm{H},-\mathrm{CH}_{2} \mathrm{NHSO}_{2}\right), 2.60\left(\mathrm{~s}, 3 \mathrm{H}, \mathrm{CH}_{3}\right), 1.62\left(\mathrm{~d}, J=6.0 \mathrm{~Hz}, 2 \mathrm{H},-\mathrm{CH}_{2}-\right) ;{ }^{13} \mathrm{C}-\mathrm{NMR}(75 \mathrm{MHz}$, $\left.\mathrm{CDCl}_{3}\right) \delta 160.2, \overline{159.3}, 147.9,143.5,142.5,140.6,140.1,139.9,137.8,131.5,130.4,130.1,129.3,128.1,127.5$, 125.6, 123.2, 120.6, 116.2, 115.3, 112.5, 106.1 (Ar-C), $55.8\left(\mathrm{OCH}_{3}\right), 40.7\left(\mathrm{CH}_{2}\right), 38.9\left(\mathrm{CH}_{2}\right), 30.2\left(\mathrm{CH}_{2}\right)$, $22.0\left(\mathrm{CH}_{3}\right)$; LC-MS $(\mathrm{m} / z)$ calculated for $\mathrm{C}_{31} \mathrm{H}_{31} \mathrm{~N}_{5} \mathrm{O}_{4} \mathrm{~S}: 553.21$, found: $554.0(\mathrm{M}+1)^{+}$.

N-(3-((4-(3-(3-Methoxyphenyl)-1-phenyl-1H-pyrazol-4-yl)pyridin-2-yl)amino)propyl)-4-(trifluoromethyl) benzenesulfonamide (2g); White solid (71\%); mp 150-152 ${ }^{\circ} \mathrm{C} ;{ }^{1} \mathrm{H}-\mathrm{NMR}\left(300 \mathrm{MHz}, \mathrm{CDCl}_{3}\right) \delta 7.84-7.81$ (m, 4H, Ar-H), 7.61 (d, J = 6.0 Hz, 2H, Ar-H), 7.49 (brs, 1H, NH), 7.21-7.16 (m, 6H, Ar-H), 6.82 (d, $J=6.0 \mathrm{~Hz}, 1 \mathrm{H}, \mathrm{Ar}-\mathrm{H}), 6.68(\mathrm{~d}, J=5.4,1 \mathrm{H}, \mathrm{Ar}-\mathrm{H}), 6.60(\mathrm{~s}, 1 \mathrm{H}, \mathrm{Ar}-\mathrm{H}), 6.33$ (d, J = 3.9 Hz, Ar-H), 6.14 (s, 
$1 \mathrm{H}, \mathrm{Ar}-\mathrm{H}), 4.52$ (brs, $1 \mathrm{H}, \mathrm{NH}), 3.56$ (s, 3H, OCH $), 3.26$ (brs, $\left.2 \mathrm{H}, \mathrm{NH}-\mathrm{CH}_{2}-\right), 2.89$ (brs, $2 \mathrm{H}, \mathrm{CH}_{2} \mathrm{NHSO}_{2}$ ), 1.95 (brs, $\left.2 \mathrm{H},-\mathrm{CH}_{2}-\right) ;{ }^{13} \mathrm{C}-\mathrm{NMR}\left(75 \mathrm{MHz}, \mathrm{CDCl}_{3}\right) \delta 159.7,158.8,147.1,142.2,140.1,139.5,139.3,131.0$, 129.9, 128.8, 127.6, 127.4, 126.1, 126.0, 125.1, 122.7, 119.9, 115.7, 114.8, 112.2, 106.1 (Ar-C), $55.2\left(\mathrm{OCH}_{3}\right)$, $40.1\left(\mathrm{CH}_{2}\right), 38.3\left(\mathrm{CH}_{2}\right), 30.1\left(\mathrm{CH}_{2}\right)$; LC-MS $(\mathrm{m} / z)$ calculated for $\mathrm{C}_{31} \mathrm{H}_{28} \mathrm{~F}_{3} \mathrm{~N}_{5} \mathrm{O}_{3} \mathrm{~S}: 607.19$, found: 608.0 $(\mathrm{M}+1)^{+}$.

3-Fluoro-N-(3-((4-(3-(3-methoxyphenyl)-1-phenyl-1H-pyrazol-4-yl)pyridin-2-yl)amino) propyl) benzenesulfonamide (2h); White solid (76\%); mp 120-122 ${ }^{\circ} \mathrm{C} ;{ }^{1} \mathrm{H}-\mathrm{NMR}\left(300 \mathrm{MHz}, \mathrm{CDCl}_{3}\right) \delta 7.94$ (s, 1H, Ar-H), 7.91 (d, J = 6.0 Hz, 1H, Ar-H), 7.30-7.22 (m, 10H, Ar-H), 6.93 (dd, J = $2.0 \mathrm{~Hz}, J=6.0 \mathrm{~Hz}$, $1 \mathrm{H}, \mathrm{Ar}-\mathrm{H}), 6.89(\mathrm{~d}, J=6.0 \mathrm{~Hz}, 1 \mathrm{H}, \mathrm{Ar}-\mathrm{H}), 6.70(\mathrm{~s}, 1 \mathrm{H}, \mathrm{Ar}-\mathrm{H}), 6.44(\mathrm{~d}, J=6.0 \mathrm{~Hz}, 1 \mathrm{H}, \mathrm{Ar}-\mathrm{H}), 6.24(\mathrm{~s}$, $1 \mathrm{H}, \mathrm{Ar}-\mathrm{H}), 4.74(\mathrm{~s}, 1 \mathrm{H}, \mathrm{NH}), 3.67\left(\mathrm{~s}, 3 \mathrm{H}, \mathrm{OCH}_{3}\right), 3.31$ (brs, $\left.2 \mathrm{H}, \mathrm{NH}-\mathrm{CH}_{2}-\right), 2.98(\mathrm{t}, J=6.0 \mathrm{~Hz}, 2 \mathrm{H}$, $\mathrm{CH}_{2} \mathrm{NHSO}_{2}$ ), 1.65 (brs, $2 \mathrm{H},-\mathrm{CH}_{2}$ ) $) ;{ }^{13} \mathrm{C}-\mathrm{NMR}\left(75 \mathrm{MHz}, \mathrm{CDCl}_{3}\right) \delta 159.6,158.8,147.2,142.5,140.1,139.5$, $139.3,131.0,130.8,130.7,129.9,128.8,127.6,125.1,122.7,122.7,120.0,119.5,119.2,115.7,114.8,114.4$, 114.1, 112.1, $105.9(\mathrm{Ar}-\mathrm{C}), 55.2\left(\mathrm{OCH}_{3}\right), 40.1\left(\mathrm{CH}_{2}\right), 38.2\left(\mathrm{CH}_{2}\right), 29.9\left(\mathrm{CH}_{2}\right)$; LC-MS $(\mathrm{m} / \mathrm{z})$ calculated for $\mathrm{C}_{30} \mathrm{H}_{28} \mathrm{FN}_{5} \mathrm{O}_{3} \mathrm{~S}: 557.19$, found: $558.0(\mathrm{M}+1)^{+}$.

N-(3-((4-(3-(3-Methoxyphenyl)-1-phenyl-1H-pyrazol-4-yl)pyridin-2-yl)amino)propyl)naphthalene-1sulfonamide (2i); White solid (66\%); mp 134-136 ${ }^{\circ} \mathrm{C} ;{ }^{1} \mathrm{H}-\mathrm{NMR}\left(300 \mathrm{MHz}, \mathrm{CDCl}_{3}\right) \delta 8.40(\mathrm{~s}, 1 \mathrm{H}, \mathrm{Ar}-\mathrm{H})$, 7.97-7.78 (m, 5H, Ar-H), $7.60(\mathrm{~d}, J=6.0 \mathrm{~Hz}, 2 \mathrm{H}, \mathrm{Ar}-\mathrm{H}), 730-7.22(\mathrm{~m}, 6 \mathrm{H}, \mathrm{Ar}-\mathrm{H}), 6.91(\mathrm{~d}, J=9.0 \mathrm{~Hz}, 1 \mathrm{H}$, Ar-H), $6.77(\mathrm{~d}, J=6.0 \mathrm{~Hz}, 1 \mathrm{H}, \mathrm{Ar}-\mathrm{H}), 6.70(\mathrm{~s}, 1 \mathrm{H}, \mathrm{Ar}-\mathrm{H}), 6.45(\mathrm{~d}, J=6.0 \mathrm{~Hz}, 1 \mathrm{H}, \mathrm{Ar}-\mathrm{H}), 6.20(\mathrm{~s}, 1 \mathrm{H}$, $\mathrm{Ar}-\mathrm{H}), 4.61(\mathrm{~s}, 1 \mathrm{H}, \mathrm{NH}), 3.65\left(\mathrm{~s}, 3 \mathrm{H}, \mathrm{OCH}_{3}\right), 3.31$ (brs, $\left.2 \mathrm{H}, \mathrm{NH}-\mathrm{CH}_{2}-\right), 3.00\left(\mathrm{~s}, 2 \mathrm{H}, \mathrm{CH}_{2} \mathrm{NHSO}_{2}\right), 1.64$ (brs, $\left.2 \mathrm{H},-\mathrm{CH}_{2}-\right) ;{ }^{13} \mathrm{C}-\mathrm{NMR}\left(75 \mathrm{MHz}, \mathrm{CDCl}_{3}\right) \delta 159.6,158.8,147.5,142.0,140.1,139.6,139.4,137.2,134.6$, 132.1, 131.0, 129.9, 129.3, 129.1, 128.8, 128.5, 128.1, 127.8, 127.6, 127.4, 125.1, 122.7, 122.4, 120.0, 115.7, 114.8, 112.1, $105.8(\mathrm{Ar}-\mathrm{C}), 55.2\left(\mathrm{OCH}_{3}\right), 40.1\left(\mathrm{CH}_{2}\right), 38.2\left(\mathrm{CH}_{2}\right), 29.9\left(\mathrm{CH}_{2}\right)$; LC-MS $(m / z)$ calculated for $\mathrm{C}_{30} \mathrm{H}_{28} \mathrm{FN}_{5} \mathrm{O}_{3} \mathrm{~S}: 589.21$, found: $590.0(\mathrm{M}+1)^{+}$.

3.6. General Procedure for Synthesis of N-(2-((4-(3-(3-hydroxyphenyl)-1-phenyl-1H-pyrazol-4-yl)pyridin-2-yl) amino)ethyl)benzenesulfonamide (3a), N-(2-((4-(3-(3-hydroxyphenyl)-1-phenyl-1H-pyrazol-4-yl)pyridin-2-yl) amino)ethyl)benzenesulfonamide (3b-h), N-(3-((4-(3-(3-hydroxyphenyl)-1-phenyl-1H-pyrazol-4-yl)pyridin2-yl)amino)propyl)benzenesulfonamide (4a) and N-(3-((4-(3-(3-hydroxyphenyl)-1-phenyl-1H-pyrazol-4-yl) pyridin-2-yl)amino)propyl) (substituted)benzenesulfonamide $(\mathbf{4} \mathbf{b}-\mathbf{h})$

To a mixture of compound (1a-i) or $(\mathbf{2 a}-\mathbf{i})(0.1 \mathrm{mmol})$ in methylene chloride $(5 \mathrm{~mL}), \mathrm{BBr}_{3}(0.13 \mathrm{~g}$, $1.0 \mathrm{mmol}$ ) was added dropwise at $-78{ }^{\circ} \mathrm{C}$ under nitrogen, and the reaction mixture was stirred at $0{ }^{\circ} \mathrm{C}$ for $24 \mathrm{~h}$. The mixture was quenched with saturated aqueous $\mathrm{NaHCO}_{3}$. Ethyl acetate $(10 \mathrm{~mL})$ was added and the organic layer was separated. The aqueous layer was extracted with ethyl acetate $(3 \times 10 \mathrm{~mL})$. The combined organic layer extracts were washed with brine and dried over anhydrous $\mathrm{Na}_{2} \mathrm{SO}_{4}$. The organic solvent was evaporated under reduced pressure and the residue was purified by column chromatography.

N-(2-((4-(3-(3-Hydroxyphenyl)-1-phenyl-1H-pyrazol-4-yl)pyridin-2-yl)amino)ethyl) benzenesulfonamide (3a); light brown solid (36\%); mp 100-102 ${ }^{\circ} \mathrm{C} ;{ }^{1} \mathrm{H}-\mathrm{NMR}\left(400 \mathrm{MHz}, \mathrm{CD}_{3} \mathrm{OD}\right) \delta 8.05(\mathrm{~s}, 1 \mathrm{H}, \mathrm{Ar}-\mathrm{H}), 7.83(\mathrm{~d}$, $J=7.2 \mathrm{~Hz}, 2 \mathrm{H}, \mathrm{Ar}-\mathrm{H}), 7.76(\mathrm{~d}, J=5.6 \mathrm{~Hz}, 1 \mathrm{H}, \mathrm{Ar}-\mathrm{H}), 7.54-7.50(\mathrm{~m}, 3 \mathrm{H}, \mathrm{Ar}-\mathrm{H}), 7.37-7.34(\mathrm{~m}, 3 \mathrm{H}, \mathrm{Ar}-\mathrm{H})$, 7.29-7.27 (m, 2H, Ar-H), $7.18(\mathrm{t}, J=8.0 \mathrm{~Hz}, 1 \mathrm{H}, \mathrm{Ar}-\mathrm{H}), 6.84-6.81(\mathrm{~m}, 1 \mathrm{H}, \mathrm{Ar}-\mathrm{H}), 6.67-6.64(\mathrm{~m}, 2 \mathrm{H}, \mathrm{Ar}-\mathrm{H})$, $6.46(\mathrm{dd}, J=5.2 \mathrm{~Hz}, J=1.2 \mathrm{~Hz}, 1 \mathrm{H}, \mathrm{Ar}-\mathrm{H}), 6.38(\mathrm{~s}, 1 \mathrm{H}, \mathrm{Ar}-\mathrm{H}), 3.26\left(\mathrm{t}, J=6.0 \mathrm{~Hz}, 2 \mathrm{H}, \mathrm{NH}-\mathrm{CH}_{2}-\right), 2.99(\mathrm{t}$, $\left.J=6.0 \mathrm{~Hz}, 2 \mathrm{H},-\mathrm{CH}_{2} \mathrm{NHSO}_{2}\right),{ }^{13} \mathrm{C}-\mathrm{NMR}\left(100 \mathrm{MHz}, \mathrm{CD}_{3} \mathrm{OD}\right) \delta 158.6,157.6,149.5,141.9,140.3,139.3$, 138.9, 132.1, 130.7, 129.7, 128.7, 128.5, 127.7, 126.5, 121.2, 119.7, 116.8, 115.9, 112.3, 105.7 (Ar-C), 42.2 $\left(\mathrm{CH}_{2}\right), 40.9\left(\mathrm{CH}_{2}\right)$; $\mathrm{LC}-\mathrm{MS}(\mathrm{m} / \mathrm{z})$ calculated for $\mathrm{C}_{28} \mathrm{H}_{25} \mathrm{~N}_{5} \mathrm{O}_{3} \mathrm{~S}: 511.17$, found: $512.0(\mathrm{M}+1)^{+}$.

4-Bromo-N-(2-((4-(3-(3-hydroxyphenyl)-1-phenyl-1H-pyrazol-4-yl)pyridin-2-yl)amino)ethyl)

benzenesulfonamide (3b); Buff solid (30\%); mp 178-180 ${ }^{\circ} \mathrm{C} ;{ }^{1} \mathrm{H}-\mathrm{NMR}\left(400 \mathrm{MHz}, \mathrm{CDCl}_{3}\right) \delta 7.88$ $(\mathrm{s}, 1 \mathrm{H}, \mathrm{Ar}-\mathrm{H}), 7.56(\mathrm{~d}, J=6.0 \mathrm{~Hz}, 3 \mathrm{H}, \mathrm{Ar}-\mathrm{H}), 7.42(\mathrm{~d}, J=8.1 \mathrm{~Hz}, 2 \mathrm{H}, \mathrm{Ar}-\mathrm{H}), 7.17-7.08(\mathrm{~m}, 6 \mathrm{H}, \mathrm{Ar}-\mathrm{H})$, $6.80(\mathrm{~d}, J=7.6 \mathrm{~Hz}, 1 \mathrm{H}, \mathrm{Ar}-\mathrm{H}), 6.64(\mathrm{~s}, 1 \mathrm{H}, \mathrm{Ar}-\mathrm{H}), 6.58(\mathrm{~d}, J=7.1 \mathrm{~Hz}, 1 \mathrm{H}, \mathrm{Ar}-\mathrm{H}), 6.37(\mathrm{~d}, J=4.7 \mathrm{~Hz}, 1 \mathrm{H}$, Ar-H), 6.17 (s, 1H, Ar-H), 5.08 (brs, $1 \mathrm{H}, \mathrm{NH}$ ), 3.13 (brs, $2 \mathrm{H}, \mathrm{NH}-\mathrm{CH}_{2}-$ ), 2.93 (brs, $2 \mathrm{H},-\mathrm{CH}_{2} \mathrm{NHSO}_{2}$ ); ${ }^{13} \mathrm{C}-\mathrm{NMR}\left(100 \mathrm{MHz}, \mathrm{CD}_{3} \mathrm{OD}\right) \delta 158.0,157.3,146.6,146.4,142.4,140.6,139.1,138.7,132.3,132.1,130.7$, 
129.0, 128.5, 128.3, 127.4, 125.2, 124.9, 119.6, 117.4, 117.2, 116.2, 112.2, $105.4(\mathrm{Ar}-\mathrm{C}), 42.9\left(\mathrm{CH}_{2}\right), 41.5$ $\left(\mathrm{CH}_{2}\right)$; LC-MS $(m / z)$ calculated for $\mathrm{C}_{28} \mathrm{H}_{24} \mathrm{BrN}_{5} \mathrm{O}_{3} \mathrm{~S}: 589.17$, found: $590.0(\mathrm{M}+1)^{+}$.

4-Chloro-N-(2-((4-(3-(3-hydroxyphenyl)-1-phenyl-1H-pyrazol-4-yl)pyridin-2-yl)amino)ethyl) benzenesulfonamide (3c); Light brown solid (41\%); mp $100-102{ }^{\circ} \mathrm{C} ;{ }^{1} \mathrm{H}-\mathrm{NMR}\left(400 \mathrm{MHz}, \mathrm{CD}_{3} \mathrm{OD}\right) \delta$ 8.05 (s, 1H, Ar-H), 7.78-7.74 (m, 3H, Ar-H), 7.47 (d, J = 8.8 Hz, 2H, Ar-H), 7.35-7.32 (m 3H, Ar-H), 7.28-7.27 (m, 2H, Ar-H), $7.18(\mathrm{t}, J=8.0 \mathrm{~Hz}, 1 \mathrm{H}, \mathrm{Ar}-\mathrm{H}), 6.84-6.81(\mathrm{~m}, 1 \mathrm{H}, \mathrm{Ar}-\mathrm{H}), 6.67(\mathrm{~s}, 1 \mathrm{H}, \mathrm{Ar}-\mathrm{H})$, $6.66(\mathrm{t}, J=2.0 \mathrm{~Hz}, 1 \mathrm{H}, \mathrm{Ar}-\mathrm{H}), 6.47(\mathrm{dd}, J=5.2 \mathrm{~Hz}, J=1.2 \mathrm{~Hz}, 1 \mathrm{H}, \mathrm{Ar}-\mathrm{H}), 6.34(\mathrm{~s}, 1 \mathrm{H}, \mathrm{Ar}-\mathrm{H}), 3.25(\mathrm{t}$, $\left.J=6.0 \mathrm{~Hz}, 2 \mathrm{H}, \mathrm{NH}-\mathrm{CH}_{2}-\right), 3.01\left(\mathrm{t}, J=6.0 \mathrm{~Hz}, 2 \mathrm{H},-\mathrm{CH}_{2} \mathrm{NHSO}_{2}\right),{ }^{13} \mathrm{C}-\mathrm{NMR}\left(100 \mathrm{MHz}, \mathrm{CD}_{3} \mathrm{OD}\right) \delta 158.5$, 157.6, 146.5, 1141.9, 14.0.9, 139.3, 139.1, 138.9, 138.2, 130.7, 129.8, 129.2, 129.0, 128.9, 128.5, 128.2, 127.7, $126.2,121.2,119.7,116.9,115.9,111.3,105.6(\mathrm{Ar}-\mathrm{C}), 42.2\left(\mathrm{CH}_{2}\right), 40.8\left(\mathrm{CH}_{2}\right)$; LC-MS $(\mathrm{m} / z)$ calculated for $\mathrm{C}_{28} \mathrm{H}_{24} \mathrm{ClN}_{5} \mathrm{O}_{3} \mathrm{~S}: 545.13$, found: $546.0(\mathrm{M}+1)^{+}$.

4-Fluoro-N-(2-((4-(3-(3-hydroxyphenyl)-1-phenyl-1H-pyrazol-4-yl)pyridin-2-yl)amino)ethyl) benzenesulfonamide (3d); Light yellow solid (40\%); mp 106-108 ${ }^{\circ} \mathrm{C} ;{ }^{1} \mathrm{H}-\mathrm{NMR}\left(400 \mathrm{MHz}, \mathrm{CDCl}_{3}\right) \delta 7.90$ (s, 1H, Ar-H), 7.78-7.75 (m, 2H, Ar-H), $7.60(\mathrm{~d}, J=8.0 \mathrm{~Hz}, 1 \mathrm{H}, \mathrm{Ar}-\mathrm{H}), 7.20(\mathrm{~s}, 5 \mathrm{H}, \mathrm{Ar}-\mathrm{H}), 7.12(\mathrm{t}, J=8.0 \mathrm{~Hz}$, $1 \mathrm{H}, \mathrm{Ar}-\mathrm{H}), 7.03(\mathrm{t}, J=8.0 \mathrm{~Hz}, 2 \mathrm{H}, \mathrm{Ar}-\mathrm{H}), 6.83(\mathrm{~d}, J=8.0 \mathrm{~Hz}, 1 \mathrm{H}, \mathrm{Ar}-\mathrm{H}), 6.67(\mathrm{~s}, 1 \mathrm{H}, \mathrm{Ar}-\mathrm{H}), 6.61(\mathrm{~d}$, $J=8.0 \mathrm{~Hz}, 1 \mathrm{H}, \mathrm{Ar}-\mathrm{H}), 6.40(\mathrm{~d}, J=8.0 \mathrm{~Hz}, 1 \mathrm{H}, \mathrm{Ar}-\mathrm{H}), 6.22(\mathrm{~s}, 1 \mathrm{H}, \mathrm{Ar}-\mathrm{H}) 3.18\left(\mathrm{~s}, 2 \mathrm{H}, \mathrm{NH}-\mathrm{CH}_{2}-\right), 2.97(\mathrm{~s}$, $\left.2 \mathrm{H},-\mathrm{CH}_{2} \mathrm{NHSO}_{2}\right),{ }^{13} \mathrm{C}-\mathrm{NMR}\left(100 \mathrm{MHz}, \mathrm{CDCl}_{3}\right) \delta 166.1,163.6,158.1,157.3,146.6,142.4,140.6,139.2$, 135.7, 130.7, 130.2, 129.7, 129.6, 128.8, 127.8, 125.1, 121.7, 119.6, 116.7, 116.3, 116.1, 112.3, 105.5 (Ar-C), $42.9\left(\mathrm{CH}_{2}\right), 41.6\left(\mathrm{CH}_{2}\right)$; LC-MS $(m / z)$ calculated for $\mathrm{C}_{28} \mathrm{H}_{24} \mathrm{FN}_{5} \mathrm{O}_{3} \mathrm{~S}: 529.59$, found: $530.0(\mathrm{M}+1)^{+}$.

$\mathrm{N}-(2-((4-(3-(3-H y d r o x y p h e n y l)-1-p h e n y l-1 H-p y r a z o l-4-y l) p y r i d i n-2-y l) a m i n o) e t h y l)-4-$ methylbenzenesulfonamide (3e); Yellow solid (38\%); mp 114-116 ${ }^{\circ} \mathrm{C} ;{ }^{1} \mathrm{H}-\mathrm{NMR}\left(400 \mathrm{MHz}, \mathrm{CDCl}_{3}\right) \delta 7.91$ (s, 1H, Ar-H), 7.69 (d, J = 8.0 Hz, 3H, Ar-H), 7.29-7.21 (m, 6H, Ar-H), $7.15(\mathrm{t}, J=8.0 \mathrm{~Hz}, 1 \mathrm{H}, \mathrm{Ar}-\mathrm{H}), 6.87$ $(\mathrm{d}, J=8.0 \mathrm{~Hz}, 1 \mathrm{H}, \mathrm{Ar}-\mathrm{H}), 6.72(\mathrm{~s}, 1 \mathrm{H}, \mathrm{Ar}-\mathrm{H}), 6.61(\mathrm{~d}, J=8.0 \mathrm{~Hz}, 1 \mathrm{H}, \mathrm{Ar}-\mathrm{H}), 6.44(\mathrm{~s}, 1 \mathrm{H}, \mathrm{Ar}-\mathrm{H}), 6.22(\mathrm{~s}$, $1 \mathrm{H}, \mathrm{Ar}-\mathrm{H}), 5.32$ (brs, $1 \mathrm{H}, \mathrm{NH}), 3.20$ (brs, $\left.2 \mathrm{H}, \mathrm{NH}-\mathrm{CH}_{2}-\right), 3.00-2.98\left(\mathrm{~m}, 2 \mathrm{H},-\mathrm{CH}_{2} \mathrm{NHSO}_{2}\right), 2.78(\mathrm{~s}, 3 \mathrm{H}$, $\left.\mathrm{CH}_{3}\right) ;{ }^{13} \mathrm{C}-\mathrm{NMR}\left(100 \mathrm{MHz}, \mathrm{CDCl}_{3}\right) \delta 158.2,157.1,146.7,143.4,142.4,140.4,139.3,139.2,136.7,130.8$, $130.2,129.7,128.8,127.6,127.0,125.0,121.8,119.7,116.8,112.3,105.6(\mathrm{Ar}-\mathrm{C}), 42.9\left(\mathrm{CH}_{2}\right), 41.6\left(\mathrm{CH}_{2}\right)$, 21.0 $\left(\mathrm{CH}_{3}\right)$; LC-MS $(\mathrm{m} / \mathrm{z})$ calculated for $\mathrm{C}_{29} \mathrm{H}_{29} \mathrm{~N}_{5} \mathrm{O}_{3} \mathrm{~S}: 525.59$, found: $526.0(\mathrm{M}+1)^{+}$.

$\mathrm{N}$-(2-((4-(3-(3-Hydroxyphenyl)-1-phenyl-1H-pyrazol-4-yl)pyridin-2-yl)amino)ethyl)-4-(trifluoromethyl) benzenesulfonamide (3f); White solid (40\%); mp 138-140 ${ }^{\circ} \mathrm{C} ;{ }^{1} \mathrm{H}-\mathrm{NMR}\left(400 \mathrm{MHz}, \mathrm{CDCl}_{3}\right) \delta 7.86(\mathrm{~d}$, $J=9.0 \mathrm{~Hz}, 3 \mathrm{H}, \mathrm{Ar}-\mathrm{H}), 7.62-7.57(\mathrm{~m}, 3 \mathrm{H}, \mathrm{Ar}-\mathrm{H}), 7.17(\mathrm{~s}, 5 \mathrm{H}, \mathrm{Ar}-\mathrm{H}), 7.10(\mathrm{t}, J=7.6 \mathrm{~Hz}, 1 \mathrm{H}, \mathrm{Ar}-\mathrm{H}), 6.80(\mathrm{~d}$, $J=7.1 \mathrm{~Hz}, 1 \mathrm{H}, \mathrm{Ar}-\mathrm{H}), 6.64(\mathrm{~s}, 1 \mathrm{H}, \mathrm{Ar}-\mathrm{H}), 6.58$ (d, J = 7.0 Hz, 1H, Ar-H), 6.38 (s, 1H, Ar-H), 5.32 (brs, $1 \mathrm{H}, \mathrm{NH}), 3.20$ (brs, $\left.2 \mathrm{H}, \mathrm{NH}-\mathrm{CH}_{2}-\right), 3.00-2.98\left(\mathrm{~m}, 2 \mathrm{H},-\mathrm{CH}_{2} \mathrm{NHSO}_{2}\right), 2.78\left(\mathrm{~s}, 3 \mathrm{H}, \mathrm{CH}_{3}\right) ; \mathrm{LC}-\mathrm{MS}(\mathrm{m} / \mathrm{z})$ calculated for $\mathrm{C}_{29} \mathrm{H}_{24} \mathrm{~F}_{3} \mathrm{~N}_{5} \mathrm{O}_{3} \mathrm{~S}: 579.59$, found: $580.0(\mathrm{M+1})^{+}$.

3-Fluoro-N-(2-((4-(3-(3-hydroxyphenyl)-1-phenyl-1H-pyrazol-4-yl)pyridin-2-yl)amino) ethyl) benzenesulfonamide (3g); White solid (32\%); mp 146-148 ${ }^{\circ} \mathrm{C} ;{ }^{1} \mathrm{H}-\mathrm{NMR}\left(400 \mathrm{MHz}, \mathrm{CD}_{3} \mathrm{OD}\right) \delta$ $8.05(\mathrm{~s}, 1 \mathrm{H}, \mathrm{Ar}-\mathrm{H}), 7.87(\mathrm{~d}, J=5.2 \mathrm{~Hz}, 1 \mathrm{H}, \mathrm{Ar}-\mathrm{H}), 7.64(\mathrm{~d}, J=7.6 \mathrm{~Hz}, 1 \mathrm{H}, \mathrm{Ar}-\mathrm{H}), 7.56-7.51(\mathrm{~m}, 2 \mathrm{H}, \mathrm{Ar}-\mathrm{H})$, 7.37-7.28 (m, 6H, Ar-H), $7.19(\mathrm{t}, J=8.0 \mathrm{~Hz}, 1 \mathrm{H}, \mathrm{Ar}-\mathrm{H}), 6.82(\mathrm{~d}, J=8.0 \mathrm{~Hz}, 1 \mathrm{H}, \mathrm{Ar}-\mathrm{H}), 6.68-6.65(\mathrm{~m}$, 2H, Ar-H), $6.47(\mathrm{~d}, J=5.6 \mathrm{~Hz}, 1 \mathrm{H}, \mathrm{Ar}-\mathrm{H}), 6.37(\mathrm{~s}, 1 \mathrm{H}, \mathrm{Ar}-\mathrm{H}), 3.27\left(\mathrm{t}, J=5.2 \mathrm{~Hz}, 2 \mathrm{H}, \mathrm{NH}-\mathrm{CH}_{2}-\right), 3.02(\mathrm{t}$, $\left.J=6.0 \mathrm{~Hz}, 2 \mathrm{H},-\mathrm{CH}_{2} \mathrm{NHSO}_{2}\right) ;{ }^{13} \mathrm{C}-\mathrm{NMR}\left(75 \mathrm{MHz}, \mathrm{CD}_{3} \mathrm{OD}\right) \delta 163.6,161.1,158.6,157.6,146.6,142.6$, 141.9, 139.3, 138.9, 130.8, 130.0, 130.7, 129.7, 128.5, 127.7, 125.2, 122.5, 121.1, 119.7, 119.1, 118.8, 116.8, 113.7, 113.5, 111.3, $105.7(\mathrm{Ar}-\mathrm{C}), 42.2\left(\mathrm{CH}_{2}\right), 40.8\left(\mathrm{CH}_{2}\right)$; LC-MS $(\mathrm{m} / z)$ calculated for $\mathrm{C}_{28} \mathrm{H}_{24} \mathrm{FN}_{5} \mathrm{O}_{3} \mathrm{~S}$ : 529.16, found: $530.0(\mathrm{M}+1)^{+}$.

N-(2-((4-(3-(3-Hydroxyphenyl)-1-phenyl-1H-pyrazol-4-yl)pyridin-2-yl)amino)ethyl)naphthalene-1sulfonamide (3h); White solid (33\%); mp 146-148 ${ }^{\circ} \mathrm{C} ;{ }^{1} \mathrm{H}-\mathrm{NMR}\left(400 \mathrm{MHz}, \mathrm{CDCl}_{3}\right) \delta 8.37$ (s, $\left.1 \mathrm{H}, \mathrm{Ar}-\mathrm{H}\right)$, 7.87-7.73 (m, 5H, Ar-H), 7.61-7.51 (m, 3H, Ar-H), $7.22(\mathrm{~d}, J=4.0 \mathrm{~Hz}, 5 \mathrm{H}, \mathrm{Ar}-\mathrm{H}), 7.11(\mathrm{t}, J=8.0 \mathrm{~Hz}$, $1 \mathrm{H}, \mathrm{Ar}-\mathrm{H}), 6.84(\mathrm{dd}, J=8.0 \mathrm{~Hz}, J=4.0 \mathrm{~Hz}, 1 \mathrm{H}, \mathrm{Ar}-\mathrm{H}), 6.69(\mathrm{t}, J=4.0 \mathrm{~Hz}, 1 \mathrm{H}, \mathrm{Ar}-\mathrm{H}), 6.58(\mathrm{~d}, J=8.0 \mathrm{~Hz}$, $1 \mathrm{H}, \mathrm{Ar}-\mathrm{H}), 6.38(\mathrm{dd}, J=8.0 \mathrm{~Hz}, J=4.0 \mathrm{~Hz}, 1 \mathrm{H}, \mathrm{Ar}-\mathrm{H}), 6.15$ (s, 1H, Ar-H), 5.03 (brs, 1H, NH), 3.19 (brs, $\left.2 \mathrm{H}, \mathrm{NH}-\mathrm{CH}_{2}-\right), 3.02\left(\mathrm{t}, J=8.0 \mathrm{~Hz}, 2 \mathrm{H},-\mathrm{CH}_{2} \mathrm{NHSO}_{2}\right) ;{ }^{13} \mathrm{C}-\mathrm{NMR}\left(75 \mathrm{MHz}, \mathrm{CDCl}_{3}\right) \delta$ 158.0, 157.2, 146.5, $142.4,140.5,139.2$, 136.4, 134.7, 132.0, 130.7, 130.2, 129.4, 129.2, 128.8, 128.3, 127.8, 127.7, 127.4, 125.0, 
122.1, 121.7, 119.6, 117.3, 116.8, 112.3, $105.5(\mathrm{Ar}-\mathrm{C}), 43.0\left(\mathrm{CH}_{2}\right), 41.6\left(\mathrm{CH}_{2}\right)$; LC-MS $(\mathrm{m} / z)$ calculated for $\mathrm{C}_{32} \mathrm{H}_{27} \mathrm{~N}_{5} \mathrm{O}_{3} \mathrm{~S}: 561.66$, found: $562.0(\mathrm{M}+1)^{+}$.

N-(3-((4-(3-(3-Hydroxyphenyl)-1-phenyl-1H-pyrazol-4-yl)pyridin-2-yl)amino)propyl)

benzenesulfonamide (4a); White solid (37\%); mp 154-156 ${ }^{\circ} \mathrm{C}$; ${ }^{1} \mathrm{H}-\mathrm{NMR}\left(400 \mathrm{MHz}, \mathrm{CDCl}_{3}\right) \delta$ $7.92(\mathrm{~s}, 1 \mathrm{H}, \mathrm{Ar}-\mathrm{H}), 7.81-7.74(\mathrm{~m}, 3 \mathrm{H}, \mathrm{Ar}-\mathrm{H}), 7.51(\mathrm{~d}, J=7.2 \mathrm{~Hz}, 1 \mathrm{H}, \mathrm{Ar}-\mathrm{H}), 7.44(\mathrm{t}, J=7.6 \mathrm{~Hz}, 2 \mathrm{H}, \mathrm{Ar}-\mathrm{H})$, $7.26(\mathrm{~s}, 5 \mathrm{H}, \mathrm{Ar}-\mathrm{H}), 7.14(\mathrm{t}, J=7.9 \mathrm{~Hz}, 1 \mathrm{H}, \mathrm{Ar}-\mathrm{H}), 6.87(\mathrm{~d}, J=7.88 \mathrm{~Hz}, 1 \mathrm{H}, \mathrm{Ar}-\mathrm{H}), 6.74(\mathrm{~s}, 1 \mathrm{H}, \mathrm{Ar}-\mathrm{H}), 6.60$ $(\mathrm{d}, J=7.4 \mathrm{~Hz}, 1 \mathrm{H}, \mathrm{Ar}-\mathrm{H}), 6.51(\mathrm{~d}, J=5.3 \mathrm{~Hz}, 1 \mathrm{H}, \mathrm{Ar}-\mathrm{H}), 6.11(\mathrm{~s}, 1 \mathrm{H}, \mathrm{Ar}-\mathrm{H}), 4.83$ (brs, $1 \mathrm{H}, \mathrm{NH}), 3.06$ (brs, $\left.2 \mathrm{H}, \mathrm{NH}-\mathrm{CH}_{2}-\right), 2.88\left(\mathrm{~d}, J=5.8 \mathrm{~Hz}, 2 \mathrm{H},-\mathrm{CH}_{2} \mathrm{NHSO}_{2}\right), 1.53\left(\mathrm{p}, J=5.8 \mathrm{~Hz}, 2 \mathrm{H}, \mathrm{CH}_{2} \mathrm{CH}_{2} \mathrm{CH}_{2}\right) ; \mathrm{LC}-\mathrm{MS}$ $(m / z)$ calculated for $\mathrm{C}_{29} \mathrm{H}_{27} \mathrm{~N}_{5} \mathrm{O}_{3} \mathrm{~S}: 525.63$, found: $526.0(\mathrm{M}+1)^{+}$.

4-Bromo-N-(3-((4-(3-(3-hydroxyphenyl)-1-phenyl-1H-pyrazol-4-yl)pyridin-2-yl)amino) propyl) benzenesulfonamide (4b); Light yellow solid (42\%); mp 184-186 ${ }^{\circ} \mathrm{C} ;{ }^{1} \mathrm{H}-\mathrm{NMR}\left(400 \mathrm{MHz}, \mathrm{CD}_{3} \mathrm{OD}\right) \delta$ $8.06(\mathrm{~s}, 1 \mathrm{H}, \mathrm{Ar}-\mathrm{H}), 7.79$ (d, J = 5.2 Hz, 1H, Ar-H), 7.80-7.67 (m, 4H, Ar-H), 7.37-7.34 (m, 3H, Ar-H), 7.29-7.27 (m, 2H, Ar-H), $7.19(\mathrm{t}, J=8.4 \mathrm{~Hz}, 1 \mathrm{H}, \mathrm{Ar}-\mathrm{H}), 6.84-6.81(\mathrm{~m}, 1 \mathrm{H}, \mathrm{Ar}-\mathrm{H}), 6.68(\mathrm{~s}, 1 \mathrm{H}, \mathrm{Ar}-\mathrm{H}), 6.66$ $(\mathrm{s}, 1 \mathrm{H}, \mathrm{Ar}-\mathrm{H}), 6.51(\mathrm{dd}, J=5.6 \mathrm{~Hz}, J=1.2 \mathrm{~Hz}, 1 \mathrm{H}, \mathrm{Ar}-\mathrm{H}), 6.34(\mathrm{~s}, 1 \mathrm{H}, \mathrm{Ar}-\mathrm{H}), 3.14(\mathrm{t}, J=8.0 \mathrm{~Hz}, 2 \mathrm{H}$, $\left.\mathrm{NH}-\mathrm{CH}_{2}-\right), 2.93\left(\mathrm{t}, J=8.0 \mathrm{~Hz}, 2 \mathrm{H},-\mathrm{CH}_{2} \mathrm{NHSO}_{2}\right) ; 1.61\left(\mathrm{~d}, J=6.0 \mathrm{~Hz}, 2 \mathrm{H}, \mathrm{CH}_{2} \mathrm{CH}_{2} \mathrm{CH}_{2}\right) ;{ }^{13} \mathrm{C}-\mathrm{NMR}(100$ $\left.\mathrm{MHz}, \mathrm{CD}_{3} \mathrm{OD}\right) \delta 158.9,157.6,146.6,141.9,140.9,139.7,139.3,138.9,132.0,130.8,129.8,128.5,128.3$, 127.7, 126.6, 125.2, 121.2, 119.8, 116.8, 115.9, 110.9, $105.4(\mathrm{Ar}-\mathrm{C}), 40.2\left(\mathrm{CH}_{2}\right), 38.1\left(\mathrm{CH}_{2}\right), 28.8\left(\mathrm{CH}_{2}\right)$; LC-MS $(m / z)$ calculated for $\mathrm{C}_{29} \mathrm{H}_{26} \mathrm{BrN}_{5} \mathrm{O}_{3} \mathrm{~S}: 604.10$, found: $605.0(\mathrm{M}+1)^{+}$.

4-Chloro-N-(3-((4-(3-(3-hydroxyphenyl)-1-phenyl-1H-pyrazol-4-yl)pyridin-2-yl)amino) propyl) benzenesulfonamide (4c); White solid (52\%); mp 166-168 ${ }^{\circ} \mathrm{C} ;{ }^{1} \mathrm{H}-\mathrm{NMR}\left(400 \mathrm{MHz}, \mathrm{CD}_{3} \mathrm{OD}\right) \delta 8.06$ (s, 1H, Ar-H), 7.87-7.75 (m, 3H, Ar-H), 7.60-7.46 (m, 2H, Ar-H), 7.36 (t, J = 5.8 Hz, 3H, Ar-H), 7.32-7.26 $(\mathrm{m}, 2 \mathrm{H}, \mathrm{Ar}-\mathrm{H}), 7.19(\mathrm{t}, J=7.9 \mathrm{~Hz}, 1 \mathrm{H}, \mathrm{Ar}-\mathrm{H}), 6.83(\mathrm{ddd}, J=8.3 \mathrm{~Hz}, 2.3 \mathrm{~Hz}, 0.8 \mathrm{~Hz}, 1 \mathrm{H}, \mathrm{Ar}-\mathrm{H}), 6.67(\mathrm{t}$, $J=5.0 \mathrm{~Hz}, 2 \mathrm{H}, \mathrm{Ar}-\mathrm{H}), 6.51(\mathrm{dd}, J=5.5 \mathrm{~Hz}, 1.4 \mathrm{~Hz}, 1 \mathrm{H}, \mathrm{Ar}-\mathrm{H}), 6.34(\mathrm{~s}, 1 \mathrm{H}, \mathrm{Ar}-\mathrm{H}), 3.14(\mathrm{t}, J=6.6 \mathrm{~Hz}$, $\left.2 \mathrm{H}, \mathrm{NH}-\mathrm{CH}_{2}^{-}\right), 2.93\left(\mathrm{t}, J=6.8 \mathrm{~Hz}, 2 \mathrm{H},-\mathrm{CH}_{2} \mathrm{NHSO}_{2}\right), 1.61\left(\mathrm{p}, J=6.7 \mathrm{~Hz}, 2 \mathrm{H}, \mathrm{CH}_{2} \mathrm{CH}_{2} \mathrm{CH}_{2}\right) ;{ }^{13} \mathrm{C}-\mathrm{NMR}$ $\left(100 \mathrm{MHz}, \mathrm{CD}_{3} \mathrm{OD}\right) \delta 158.9,157.6,146.7,141.9,140.9,139.3,139.2,138.9,138.3,130.8,129.8,129.0,128.5$, $128.2,127.7,125.2,121.2,119.8,116.8,115.9,110.9,105.4(\mathrm{Ar}-\mathrm{C}), 40.2\left(\mathrm{CH}_{2}\right), 38.1\left(\mathrm{CH}_{2}\right), 28.8\left(\mathrm{CH}_{2}\right)$; LC-MS $(m / z)$ calculated for $\mathrm{C}_{29} \mathrm{H}_{26} \mathrm{ClN}_{5} \mathrm{O}_{3} \mathrm{~S}: 560.7$, found: $561.0(\mathrm{M}+1)^{+}$.

4-Fluoro-N-(3-((4-(3-(3-hydroxyphenyl)-1-phenyl-1H-pyrazol-4-yl)pyridin-2-yl)amino) propyl) benzenesulfonamide (4d); White solid (45\%); mp 144-146 ${ }^{\circ} \mathrm{C} ;{ }^{1} \mathrm{H}-\mathrm{NMR}\left(400 \mathrm{MHz}, \mathrm{CD}_{3} \mathrm{OD}\right) \delta 8.06(\mathrm{~s}, 1 \mathrm{H}$, Ar-H), 7.98-7.86 (m, 2H, Ar-H), $7.80(\mathrm{~d}, J=5.5 \mathrm{~Hz}, 1 \mathrm{H}, \mathrm{Ar}-\mathrm{H}), 7.37(\mathrm{~d}, J=6.6 \mathrm{~Hz}, 3 \mathrm{H}, \mathrm{Ar}-\mathrm{H}), 7.33-7.24$ $(\mathrm{m}, 4 \mathrm{H}, \mathrm{Ar}-\mathrm{H}), 7.20(\mathrm{t}, J=7.8 \mathrm{~Hz}, 1 \mathrm{H}, \mathrm{Ar}-\mathrm{H}), 6.83(\mathrm{~d}, J=8.2 \mathrm{~Hz}, 1 \mathrm{H}, \mathrm{Ar}-\mathrm{H}), 6.67(\mathrm{~d}, J=8.4 \mathrm{~Hz}, 2 \mathrm{H}$, Ar-H), $6.51(\mathrm{~d}, J=5.5 \mathrm{~Hz}, 1 \mathrm{H}, \mathrm{Ar}-\mathrm{H}), 6.35(\mathrm{~s}, 1 \mathrm{H}, \mathrm{Ar}-\mathrm{H}), 3.15\left(\mathrm{t}, J=6.6 \mathrm{~Hz}, 2 \mathrm{H}, \mathrm{NH}-\mathrm{CH}_{2}-\right), 2.92(\mathrm{t}$, $\left.J=6.7 \mathrm{~Hz}, 2 \mathrm{H},-\mathrm{CH}_{2} \mathrm{NHSO}_{2}\right), 1.74-1.53\left(\mathrm{~m}, 2 \mathrm{H}, \mathrm{CH}_{2} \mathrm{CH}_{2} \mathrm{CH}_{2}\right) ;{ }^{13} \mathrm{C}-\mathrm{NMR}\left(100 \mathrm{MHz}, \widehat{\mathrm{CD}} \mathrm{OD}_{3}\right) \delta 158.9$, 157.6, 146.7, 141.9, 139.3, 138.8, 136.7, 130.8, 129.7, 129.5, 129.4, 128.5, 127.7, 125.2, 121.2, 119.8, 116.8, 115.9, 115.8, 115.6, 110.9, 105.4 (Ar-C), $40.2\left(\mathrm{CH}_{2}\right), 38.2\left(\mathrm{CH}_{2}\right), 28.8\left(\mathrm{CH}_{2}\right)$; LC-MS $(m / z)$ calculated for $\mathrm{C}_{29} \mathrm{H}_{26} \mathrm{FN}_{5} \mathrm{O}_{3} \mathrm{~S}: 543.17$, found: $544.0(\mathrm{M}+1)^{+}$.

N-(3-((4-(3-(3-Hydroxyphenyl)-1-phenyl-1H-pyrazol-4-yl)pyridin-2-yl)amino)propyl)-4methylbenzenesulfonamide (4e); White solid (33\%); mp 158-160 ${ }^{\circ} \mathrm{C} ;{ }^{1} \mathrm{H}-\mathrm{NMR}\left(400 \mathrm{MHz}, \mathrm{CD}_{3} \mathrm{OD}\right) \delta$ $8.06(\mathrm{~s}, 1 \mathrm{H}, \mathrm{Ar}-\mathrm{H}), 7.79$ (d, J = 5.5 Hz, 1H, Ar-H), $7.72(\mathrm{~d}, J=8.3 \mathrm{~Hz}, 2 \mathrm{H}, \mathrm{Ar}-\mathrm{H}), 7.41-7.25(\mathrm{~m}, 7 \mathrm{H}$, Ar-H), $7.19(\mathrm{t}, J=7.9 \mathrm{~Hz}, 1 \mathrm{H}, \mathrm{Ar}-\mathrm{H}), 6.83(\mathrm{ddd}, J=8.3 \mathrm{~Hz}, 2.3 \mathrm{~Hz}, 1.0 \mathrm{~Hz}, 1 \mathrm{H}, \mathrm{Ar}-\mathrm{H}), 6.71-6.61(\mathrm{~m}, 2 \mathrm{H}$, Ar-H), $6.51(\mathrm{dd}, J=5.5,1.5 \mathrm{~Hz}, 1 \mathrm{H}, \mathrm{Ar}-\mathrm{H}), 6.34(\mathrm{~s}, 1 \mathrm{H}, \mathrm{Ar}-\mathrm{H}), 3.13\left(\mathrm{t}, J=6.7 \mathrm{~Hz}, 2 \mathrm{H}, \mathrm{NH}-\mathrm{CH}_{2}-\right), 2.89$ $\left(\mathrm{t}, J=6.8 \mathrm{~Hz}, 2 \mathrm{H},-\mathrm{CH}_{2} \mathrm{NHSO}_{2}\right), 2.41\left(\mathrm{~s}, 3 \mathrm{H}, \mathrm{CH}_{3}\right), 1.60\left(\mathrm{p}, J=6.7 \mathrm{~Hz}, 2 \mathrm{H}, \mathrm{CH}_{2} \mathrm{CH}_{2} \mathrm{CH}_{2}\right) ;{ }^{13} \mathrm{C}-\mathrm{NMR}$ $\left(100 \mathrm{MHz}, \mathrm{CD}_{3} \mathrm{OD}\right) \delta 158.9,157.6,146.7,143.1,141.9,140.9,139.3,138.9,137.4,130.8,129.8,129.3,128.5$, 127.7, 126.6, 125.2, 121.2, 119.8, 116.8, 115.9, 110.9, $105.4(\mathrm{Ar}-\mathrm{C}), 40.2\left(\mathrm{CH}_{2}\right), 38.2\left(\mathrm{CH}_{2}\right), 28.9\left(\mathrm{CH}_{2}\right), 20.1$ $\left(\mathrm{CH}_{3}\right)$; LC-MS $(m / z)$ calculated for $\mathrm{C}_{30} \mathrm{H}_{29} \mathrm{~N}_{5} \mathrm{O}_{3} \mathrm{~S}: 539.20$, found: $540.0(\mathrm{M}+1)^{+}$.

N-(3-((4-(3-(3-Hydroxyphenyl)-1-phenyl-1H-pyrazol-4-yl)pyridin-2-yl)amino)propyl)-4-(trifluoromethyl) benzenesulfonamide (4f); White solid (39\%); mp 150-152 ${ }^{\circ} \mathrm{C} ;{ }^{1} \mathrm{H}-\mathrm{NMR}\left(400 \mathrm{MHz}, \mathrm{CD}_{3} \mathrm{OD}\right) \delta 8.09-7.99$ $(\mathrm{m}, 3 \mathrm{H}, \mathrm{Ar}-\mathrm{H}), 7.87(\mathrm{~d}, J=8.3 \mathrm{~Hz}, 2 \mathrm{H}, \mathrm{Ar}-\mathrm{H}), 7.80(\mathrm{~d}, J=5.5 \mathrm{~Hz}, 1 \mathrm{H}, \mathrm{Ar}-\mathrm{H}), 7.41-7.34(\mathrm{~m}, 3 \mathrm{H}, \mathrm{Ar}-\mathrm{H})$, 7.34-7.25 (m, 2H, Ar-H), 7.20 (t, J = 7.9 Hz, 1H, Ar-H), 6.83 (ddd, J = 8.3 Hz, $2.4 \mathrm{~Hz}, 0.9 \mathrm{~Hz}, 1 \mathrm{H}$, Ar-H), 6.71-6.63 (m, 2H, Ar-H), $6.52(\mathrm{dd}, J=5.6 \mathrm{~Hz}, 1.5 \mathrm{~Hz}, 1 \mathrm{H}, \mathrm{Ar}-\mathrm{H}), 6.36(\mathrm{~d}, J=6.0 \mathrm{~Hz}, 1 \mathrm{H}, \mathrm{Ar}-\mathrm{H}), 3.16(\mathrm{t}, J$ 
$\left.=6.7 \mathrm{~Hz}, 2 \mathrm{H}, \mathrm{NH}-\mathrm{CH}_{2}-\right), 2.96\left(\mathrm{t}, J=6.8 \mathrm{~Hz}, 2 \mathrm{H},-\mathrm{CH}_{2} \mathrm{NHSO}_{2}\right), 1.64\left(\mathrm{p}, J=6.7 \mathrm{~Hz}, 2 \mathrm{H}, \mathrm{CH}_{2} \underline{\mathrm{CH}_{2}} \mathrm{CH}_{2}\right)$; ${ }^{13} \mathrm{C}-\mathrm{NMR}\left(100 \mathrm{MHz}, \mathrm{CD}_{3} \mathrm{OD}\right) \delta 158.8,157.6,146.5,142.0,140.9,139.3,138.8,130.7,129.7,128.5,127.7$, 127.3, 125.9, 125.2, 121.2, 119.7, 116.8, 115.9, 110.9, $105.5(\mathrm{Ar}-\mathrm{H}), 40.2\left(\mathrm{CH}_{2}\right), 38.1\left(\mathrm{CH}_{2}\right), 28.9\left(\mathrm{CH}_{2}\right)$; LC-MS $(m / z)$ calculated for $\mathrm{C}_{30} \mathrm{H}_{26} \mathrm{~F}_{3} \mathrm{~N}_{5} \mathrm{O}_{3} \mathrm{~S}: 593.20$, found: $594.0(\mathrm{M}+1)^{+}$.

3-Fluoro-N-(3-((4-(3-(3-hydroxyphenyl)-1-phenyl-1H-pyrazol-4-yl)pyridin-2-yl)amino) propyl) benzenesulfonamide (4g); White solid (41\%); mp 120-122 ${ }^{\circ} \mathrm{C} ;{ }^{1} \mathrm{H}-\mathrm{NMR}\left(400 \mathrm{MHz}, \mathrm{CD}_{3} \mathrm{OD}\right) \delta 8.05(\mathrm{~s}, 1 \mathrm{H}$, Ar-H), $7.79(\mathrm{~d}, J=5.5 \mathrm{~Hz}, 1 \mathrm{H}, \mathrm{Ar}-\mathrm{H}), 7.67(\mathrm{~d}, J=7.9 \mathrm{~Hz}, 1 \mathrm{H}, \mathrm{Ar}-\mathrm{H}), 7.63-7.51(\mathrm{~m}, 2 \mathrm{H}, \mathrm{Ar}-\mathrm{H}), 7.41-7.25$ $(\mathrm{m}, 6 \mathrm{H}, \mathrm{Ar}-\mathrm{H}), 7.19(\mathrm{t}, J=7.9 \mathrm{~Hz}, 1 \mathrm{H}, \mathrm{Ar}-\mathrm{H}), 6.87-6.79(\mathrm{~m}, 1 \mathrm{H}, \mathrm{Ar}-\mathrm{H}), 6.67(\mathrm{t}, J=4.2 \mathrm{~Hz}, 2 \mathrm{H}, \mathrm{Ar}-\mathrm{H})$, $6.50(\mathrm{dd}, J=5.5 \mathrm{~Hz}, 1.3 \mathrm{~Hz}, 1 \mathrm{H}, \mathrm{Ar}-\mathrm{H}), 6.36(\mathrm{~s}, 1 \mathrm{H}, \mathrm{Ar}-\mathrm{H}), 3.15\left(\mathrm{t}, J=6.7 \mathrm{~Hz}, 2 \mathrm{H}, \mathrm{NH}-\mathrm{CH}_{2}-\right), 2.93(\mathrm{t}$, $\left.J=6.8 \mathrm{~Hz}, 2 \mathrm{H},-\mathrm{CH}_{2} \mathrm{NHSO}_{2}\right), 1.63\left(\mathrm{p}, J=6.7 \mathrm{~Hz}, 2 \mathrm{H}, \mathrm{CH}_{2} \mathrm{CH}_{2} \mathrm{CH}_{2}\right),{ }^{13} \mathrm{C}-\mathrm{NMR}\left(100 \mathrm{MHz}, \mathrm{CD}_{3} \mathrm{OD}\right) \delta$ 163.7, 161.2, 158.8, 157.6, 146.5, 142.7, 141.9, 140.9, 139.3, 138.9, 130.9, 130.8, 130.8, 129.8, 128.5, 127.7, 125.2, 122.5, 122.5, 121.2, 119.8, 119.1, 118.9, 116.8, 115.9, 113.7, 113.5, 110.9, $105.5(\mathrm{Ar}-\mathrm{C}), 40.2\left(\mathrm{CH}_{2}\right)$, $38.2\left(\mathrm{CH}_{2}\right), 28.9\left(\mathrm{CH}_{2}\right)$; LC-MS $(\mathrm{m} / z)$ calculated for $\mathrm{C}_{29} \mathrm{H}_{26} \mathrm{FN}_{5} \mathrm{O}_{3} \mathrm{~S}: 543.17$, found: $544.0(\mathrm{M}+1)^{+}$.

N-(3-((4-(3-(3-Hydroxyphenyl)-1-phenyl-1H-pyrazol-4-yl)pyridin-2-yl)amino)propyl)naphthalene-1sulfonamide (4h); White solid (40\%); mp 168-70 ${ }^{\circ} \mathrm{C} ;{ }^{1} \mathrm{H}-\mathrm{NMR}\left(400 \mathrm{MHz}, \mathrm{CD}_{3} \mathrm{OD}\right) \delta 8.40$ (s, $\left.1 \mathrm{H}, \mathrm{Ar}-\mathrm{H}\right)$, $8.01(\mathrm{~s}, 1 \mathrm{H}, \mathrm{Ar}-\mathrm{H}), 7.97(\mathrm{~d}, J=8.4 \mathrm{~Hz}, 2 \mathrm{H}, \mathrm{Ar}-\mathrm{H}), 7.92(\mathrm{~d}, J=8.0 \mathrm{~Hz}, 1 \mathrm{H}, \mathrm{Ar}-\mathrm{H}), 7.81$ (dd, $J=8.8 \mathrm{~Hz}, 1.6$ $\mathrm{Hz}, 1 \mathrm{H}, \mathrm{Ar}-\mathrm{H}), 7.73(\mathrm{~d}, J=5.2 \mathrm{~Hz}, 1 \mathrm{H}, \mathrm{Ar}-\mathrm{H}), 7.65-7.57(\mathrm{~m}, 2 \mathrm{H}, \mathrm{Ar}-\mathrm{H}), 7.36-7.25$ (m, 5H, Ar-H), $7.13(\mathrm{t}, J$ $=8.0 \mathrm{~Hz}, 1 \mathrm{H}, \mathrm{Ar}-\mathrm{H}), 6.79(\mathrm{dd}, J=8.4 \mathrm{~Hz}, 2.0 \mathrm{~Hz}, 1 \mathrm{H}, \mathrm{Ar}-\mathrm{H}), 6.62(\mathrm{~s}, 1 \mathrm{H}, \mathrm{Ar}-\mathrm{H}), 6.59(\mathrm{~d}, J=6.4 \mathrm{~Hz}, 1 \mathrm{H}$, Ar-H), $6.46(\mathrm{~d}, J=4.8 \mathrm{~Hz}, 1 \mathrm{H}, \mathrm{Ar}-\mathrm{H}), 6.27(\mathrm{~s}, 1 \mathrm{H}, \mathrm{Ar}-\mathrm{H}), 3.11(\mathrm{t}, J=6.8 \mathrm{~Hz}, 2 \mathrm{H}), 2.94(\mathrm{t}, J=6.8 \mathrm{~Hz}, 2 \mathrm{H}$, $\mathrm{Ar}-\mathrm{H}), 1.60(\mathrm{t}, J=6.8 \mathrm{~Hz}, 2 \mathrm{H}, \mathrm{Ar}-\mathrm{H}) ;{ }^{13} \mathrm{C}-\mathrm{NMR}\left(100 \mathrm{MHz}, \mathrm{CD}_{3} \mathrm{OD}\right) \delta 158.7,157.6,146.4,141.9,140.9$, 139.3, 138.9, 137.2, 134.7, 132.1, 130.7, 129.7, 129.1, 128.8, 128.5, 128.3, 127.7, 127.6, 127.5, 127.2, 125.2, 122.0, 121.2, 119.7, 116.8, 115.9, 110.9, $105.3(\mathrm{Ar}-\mathrm{C}), 40.2\left(\mathrm{CH}_{2}\right), 38.2\left(\mathrm{CH}_{2}\right), 28.8\left(\mathrm{CH}_{2}\right)$; LC-MS $(\mathrm{m} / z)$ calculated for $\mathrm{C}_{33} \mathrm{H}_{29} \mathrm{~N}_{5} \mathrm{O}_{3} \mathrm{~S}: 575.20$, found: $576.0(\mathrm{M}+1)^{+}$.

\subsection{Biological Evaluation}

Cell culture and sample treatment were performed as reported in the literature [38-41]. The 3-(4,5-dimethylthiazol-2-yl)-2,5-diphenyltetrazolium bromide (MTT) assay for cell viability followed the procedure previously described in the literature [38-41]. Nitrite determination was carried as described in the literature [38-41], and the $\mathrm{PGE}_{2}$ assay was carried as previously described [38-41].

\section{Conclusion}

In this article, a new series of 1,3,4-triaylpyrazole derivatives were synthesized. The new analogues were divided into four groups $\mathbf{1 a}-\mathbf{i}, \mathbf{2} \mathbf{a}-\mathbf{i}, \mathbf{3} \mathbf{a}-\mathbf{h}$, and $\mathbf{4 a}-\mathbf{h}$. All compounds were tested for their ability to inhibit nitric oxide production in LPS-induced RAW 264.7 macrophages and cell viability to measure their cytotoxic effects. Compounds 1a-i exhibited the highest NO production inhibitor activity with low toxicity profile, followed by $\mathbf{2 a}-\mathbf{I}$, then $\mathbf{4 a}-\mathbf{h}$, and finally $3 \mathbf{a}-\mathbf{h}$. Compounds $\mathbf{3 a}-\mathbf{h}$ and $\mathbf{4 a}-\mathbf{h}$ showed high cellular toxicity. Compounds $\mathbf{1 b}, \mathbf{1 d}, \mathbf{1 g}, \mathbf{2 a}$, and $\mathbf{2 c}$ had the highest activity and lowest toxicity. Compounds $\mathbf{1 b}, \mathbf{1 d}, \mathbf{1 g}, \mathbf{2} \mathbf{a}$, and $\mathbf{2 c}$ were tested for their $\mathrm{PGE}_{2}$ inhibition ability and showed $\mathrm{IC}_{50}$ values of $4.72,5.06,4.55,4.87$, and $4.68 \mu \mathrm{M}$, respectively. Compounds $\mathbf{1 b}, \mathbf{1 d}, \mathbf{1 g}, \mathbf{2 a}$, and $\mathbf{2 c}$ were assayed for their ability to inhibit iNOS and COX-2 expressions. Compounds $\mathbf{1 b}, \mathbf{1 d}$, and $\mathbf{1 g}$ exhibited a potential iNOS inhibitory effect at $20 \mu \mathrm{M}$ and slightly inhibited iNOS enzyme activity in a dose-dependent manner. We concluded that these compounds inhibit NO production by inhibiting iNOS protein expression and by inhibiting iNOS enzyme activity to a lesser extent. These compounds with good activity and relatively low toxicity profiles can be used as promising compounds for future optimization and development of potential anti-inflammatory agents.

Supplementary Materials: Spectral data of the new synthesized compounds and intermediates are available online. 
Author Contributions: M.S.A.-M.: Performed the synthetic and spectroscopic parts, participating in design of the synthetic compounds, and participated in manuscript preparation. M.I.E-G.: Target compounds design, synthesis, data interpretation, direct lab supervision, and participated in manuscript preparation. M.M.G.E.-D.: Performed mass analysis. Y.C.: Participated in synthetic and analysis part. J.C.: Participated in synthetic and analysis part. J.-S.S. and S.-Y.K.: Performed biological activity. K.-T.L.: Design and supervision of biological work. K.H.Y., D.B. and C.-H.O.: Synthesis and analysis advisor.

Funding: This work was supported by 2017 research program of Hanseo University in Korea.

Acknowledgments: The authors would like to thank Hanseo University for funding this work.

Conflicts of Interest: The authors declare no conflict of interest.

\section{References}

1. Coussens, L.M.; Werb, Z. Inflammation and cancer. Nature 2002, 420, 860-867. [CrossRef] [PubMed]

2. Balkwill, F.; Mantovani, A. Inflammation and cancer: back to Virchow? Lancet 2001, 357, 539-545. [CrossRef]

3. Chettibi, S.; Ferguson, M.W.J. Inflammation: Basic Principles and Clinical Correlates, 3rd ed.; Gallin, J.I., Snyderman, R., et al., Eds.; Lipincott, Williams and Wilkinson: Philadelphia, PA, USA, 1999; pp. 865-881.

4. Rossi, D.; Zlotnik, A. The biology of chemokines and their receptors. Annu. Rev. Immunol 2000, 18, $217-242$. [CrossRef] [PubMed]

5. Homey, B.; Muller, A.; Zlotnik, A. Chemokines: Agents for the immunotherapy of cancer? Nat. Rev. Immunol. 2002, 2, 175-184. [CrossRef] [PubMed]

6. Sastre, M.; Richardson, J.C.; Gentleman, S.M.; Brooks, D.J. Inflammatory risk factors and pathologies associated with Alzheimer's disease. Curr. Alzheimer Res. 2011, 8, 132-141. [CrossRef] [PubMed]

7. Sung, B.; Prasad, S.; Yadav, V.R.; Lavasanifar, A.; Aggarwal, B.B. Cancer and diet: How are they related? Free Rad. Res. 2011, 45, 864-879. [CrossRef] [PubMed]

8. Lee, I.A.; Bae, E.A.; Hyun, Y.J.; Kim, D.H. Dextran sulfate sodium and 2,4,6-trinitrobenzene sulfonic acid induce lipid peroxidation by the proliferation of intestinal gram-negative bacteria in mice. J. Inflamm. 2010, 7, 7. [CrossRef] [PubMed]

9. Qui, H.; Johansson, A.S.; Sjostrom, M.; Wan, M.; Schroder, O.; Palmblad, J.; Haeggstrom, J.Z. Differential induction of BLT receptor expression on human endothelial cells by lipopolysacharide, cytokines, and leukotriene B4. Proc. Natl. Acad. Sci. USA 2006, 103, 6913-6918.

10. Marletta, M.A. Nitric oxide synthase structure and mechanism. J. Biol. Chem. 1993, 268, 12231-12234. [PubMed]

11. Grisham, M.B.; Jourd, H.D.; Wink, D.A.I. Physiological chemistry of nitric oxide and its metabolites: Implications in inflammation. Am. J. Physiol. Gastrointest. Liver Physiol. 1999, 276, 315-321. [CrossRef]

12. Morikawa, A.; Koide, N.; Kato, Y.; Sugiyama, T.; Chakravortty, D.; Yoshida, T.; Yokochi, T. Augmentation ofnitric oxide production by gamma interferon in a mouse vascular endothelial cell line and its modulationby tumor necrosis factor alpha and lipopolysaccharide. Infect. Immun. 2000, 68, 6209-6214. [CrossRef] [PubMed]

13. Dennis, E.A.; Norris, P.C. Eicosanoid storm in infection and inflammation. Nat. Rev. Immunol. 2015, 15, 511-523. [CrossRef] [PubMed]

14. Nakanishi, M.; Rosenberg, D.W. Multifaceted roles of PGE2 in inflammation and cancer. Semin. Immunopathol. 2013, 35, 123-137. [CrossRef] [PubMed]

15. Gomez-Guerrero, C.; Hernandez-Vargas, P.; Lopez-Franco, O.; Ortiz-Munoz, G.; Egido, J. Mesangial cells and glomerular inflammation: From the pathogenesis to novel therapeutic approaches. Curr. Drug Targets Inflamm. Allergy 2005, 4, 341-351. [CrossRef] [PubMed]

16. Vasilakaki, S.; Pastukhov, O.; Mavromoustakos, T.; Huwiler, A.; Kokotos, G. Small peptides able to suppress prostaglandin $\mathrm{e}_{2}$ generation in renal mesangial cells. Molecules 2018, 23, 158. [CrossRef] [PubMed]

17. Yun, H.Y.; Dawson, V.L.; Dawson, T.M. Neurobiology of nitricoxide. Crit. Rev. Neurobiol. 1996, 10, $291-316$. [CrossRef] [PubMed]

18. Hinz, B.; Brune, K.J. Cyclooxygenase-2-10 years later. Pharmacol. Exp. Ther. 2002, 300, 367-375. [CrossRef]

19. Li, Y.; Geng, J.; Liu, Y.; Yu, S.; Zhao, G. Thiadiazole-A promising structure in medicinal chemistry. ChemMedChem. 2013, 8, 27-41. [CrossRef] [PubMed]

20. Yasuhiro, Y.; Hirokazu, K.; Yoji, M.; Yoshinori, O.; Masashi, F.; Noriko, Y.I.; Jun, I.; Taiji, Y.; Makoto, T.; Mitsuaki, O. Novel potent and selective $\mathrm{Ca}^{2+}$ release-activated $\mathrm{Ca}^{2+}(\mathrm{CRAC})$ channel inhibitors. Part 3: 
Synthesis and CRAC channel inhibitory activity of 4'-[(trifluoromethyl)pyrazol-1-yl] carboxanilides. Bioorg. Med. Chem. 2008, 16, 9457-9466.

21. Matwijczuk, A.; Karcz, D.; Pustuła, K.; Makowski, M.; Górecki, A.; Kluczyk, D.; Karpińska, M.M.; Niewiadomy, A.; Gagoś, M. Spectroscopic and theoretical studies of fluorescence effects in bio-active: 4-(5-(methyl-1,3,4-thiadiazol-2-yl))benzene-1,3-diol and 4-(5-(methylamino-1,3,4-thiadiazol-2-yl)) benzene-1,3-diol compounds: Effect of molecular aggregation and amino group position. J. Luminescence 2018, 201, 44-56.

22. Silva, C.F.; Pinto, D.C.; Silva, A.M. Chromones: A promising ring system for new anti-inflammatory drugs. ChemMedChem. 2016, 11, 2252-2260. [CrossRef] [PubMed]

23. Huan-Wei, T.; Jiun-Yi, S.; Ting-Yi, K.; Ting-Syun, T.; Yi-An, C.; Alexander, P.; Pi-Tai, C. Excited-state intramolecular proton-transfer reaction demonstrating anti-Kasha behavior. Chem. Sci. 2016, 7, 655-665.

24. Matwijczuk, A.; Janik, E.; Luchowski, R.; Niewiadomy, A.; Gruszecki, W.I.; Gagoś, M. Spectroscopic studies of the molecular organization of 4-([1,2,4] triazolo [4,3-a] pyridin-3-yl)-6-methylbenzene-1,3-diol in selected solvents. J. Luminescence 2018, 194, 208-218. [CrossRef]

25. Steel, H.C.; Tintinger, G.R.; Anderson, R. Comparison of the anti-inflammatory activities of imidazole antimycotics in relation to molecular structure. Chem. Biol. Drug Des. 2008, 72, 225-228. [CrossRef] [PubMed]

26. El-Gamal, M.I.; Sim, T.B.; Hong, J.H.; Cho, J.-H.; Yoo, K.H.; Oh, C.-H. Synthesis of 1H-pyrazole-1-carboxamide derivatives and their antiproliferative activity against melanoma cell line. Arch. Pharm. Chem. Life Sci. 2011, 344, 197-204. [CrossRef] [PubMed]

27. El-Gamal, M.I.; Oh, C.-H. Design and synthesis of 3-(3-chloro-4-substituted phenyl)-4-(pyridin-4-yl)-1H-pyrazole-1-carboxamide derivatives and their antiproliferative activity against melanoma cell line. Bull. Korean Chem. Soc. 2011, 32, 821-828. [CrossRef]

28. El-Gamal, M.I.; Choi, H.S.; Cho, H.G.; Hong, J.H.; Yoo, K.H.; Oh, C.H. Design, synthesis, and antiproliferative activity of 3,4-diarylpyrazole-1-carboxamide derivatives against melanoma cell line. Arch. Pharm. Chem. Life Sci. 2011, 344, 745-754. [CrossRef] [PubMed]

29. Choi, W.K.; El-Gamal, M.I.; Choi, H.S.; Baek, D.; Oh, C.H. New diarylureas and diarylamides containing 1,3,4-triarylpyrazole scaffold: Synthesis, antiproliferative evaluation against melanoma cell lines, ERK kinase inhibition, and molecular docking studies. Eur. J. Med. Chem. 2011, 46, 5754-5762. [CrossRef] [PubMed]

30. El-Gamal, M.I.; Park, Y.S.; Chi, D.Y.; Yoo, K.H.; Oh, C.H. New triarylpyrazoles as broad-spectrum anticancer agents: Design, synthesis, and biological evaluation. Eur. J. Med. Chem. 2013, 65, 315-322. [CrossRef] [PubMed]

31. El-Gamal, M.I.; Choi, H.S.; Yoo, K.H.; Baek, D.; Oh, C.H. Antiproliferative diarylpyrazole derivatives as dual inhibitors of the ERK pathway and COX-2. Chem. Biol. Drug Des. 2013, 82, 336-347. [CrossRef] [PubMed]

32. Keche, A.P.; Hatnapure, G.D.; Tale, R.H.; Rodge, A.H.; Kamble, V.M. Synthesis, anti-inflammatory and antimicrobial evaluation of novel 1-acetyl-3,5-diaryl-4,5-dihydro $(1 \mathrm{H})$ pyrazole derivatives bearing urea, thiourea and sulfonamide moieties. Bioorg. Med. Chem. Lett. 2012, 22, 6611-6615. [CrossRef] [PubMed]

33. El-Sayed, M.A.A.; Abdel-Aziz, N.I.; Abdel-Aziz, A.A.M.; El-Azab, A.S.; ElTahir, K.E.H. Synthesis, biological evaluation and selective COX-2 inhibitors and anti-inflammatory agents Part 2. Bioorg. Med. Chem. 2012, 20, 3306-3316. [PubMed]

34. Ragab, F.A.; Abdel Gawad, N.M.; Georgey, H.H.; Said, M.F. Synthesis of novel 1,3,4-trisubstituted pyrazoles as anti-inflammatory and analgesic agents. Eur. J. Med. Chem. 2013, 63, 645-654. [CrossRef] [PubMed]

35. Malvar, D.; Ferreira, R.; De Castro, R.; De Castro, L.; Freitas, A.C.; Costa, E.; Florentino, I.; Mafra, J.; De Souza, G.; Vandelinde, F. Antinociceptive, anti-inflammatory and antipyretic effects of 1.5-diphenyl-1H-Pyrazole-3- carbohydrazide, a new heterocyclic pyrazole derivative. Life Sci. 2014, 95, 81-88. [CrossRef] [PubMed]

36. Kurumbail, R.; Stevens, A.; Gierse, J.; McDonald, J.; Stegeman, R.; Pak, J.; Gildehaus, D.; Miyashiro, J.; Penning, T.; Seibert, K.; Isakson, P.; Stallings, W. Structural basis for selective inhibition of cyclooxygenase-2 by anti-inflammatory agents. Nature 1996, 384, 644-648. [CrossRef] [PubMed]

37. Norgard, B.; Pedersen, L.; Johnsen, S.P.; Tarone, R.E.; McLaughlin, J.K.; Friis, S.; Sorensen, H.T. COX-2-selective inhibitors and the risk of upper gastrointestinal bleeding in high-risk patients with previous gastrointestinal diseases: a population-based case-control study. Aliment. Pharm. Therap. 2004, 19, 817-825. [CrossRef] [PubMed] 
38. Jang, H.-L.; El-Gamal, M.I.; Choi, H.Y.; Choi, H.Y.; Lee, K.T.; Oh, C.H. Synthesis of tricyclic fused coumarin sulfonates and their inhibitory effects on LPS-induced nitric oxide and PGE 2 productions in RAW 264.7 macrophages. Bioorg. Med. Chem. Lett. 2014, 24, 571-575. [CrossRef] [PubMed]

39. El-Gamal, M.I.; Lee, W.S.; Shin, J.S.; Oh, C.H.; Lee, K.T.; Choi, J.; Myoung, N.; Baek, D. Synthesis of new tricyclic and tetracyclic fused coumarin sulfonate derivatives, and their inhibitory effects on LPS-induced nitric oxide and $\mathrm{PGE}_{2}$ productions in RAW 264.7 macrophages: Part 2. Arch. Pharm. 2016, 349, 853-863. [CrossRef] [PubMed]

40. El-Gamal, M.I.; Abdel-Maksoud, M.S.; Gamal El-Din, M.M.; Shin, J.S.; Lee, K.T.; Yoo, K.H.; Oh, C.H. Synthesis, in vitro antiproliferative and antiinflammatory activities, and kinase inhibitory effects of new 1,3,4-triarylpyrazole derivatives. Anti-Cancer Agents Med. Chem. 2017, 17, 75-84. [CrossRef]

41. Park, B.-J.; El-Gamal, M.I.; Lee, W.S.; Shin, J.S.; Yoo, K.H.; Lee, K.T.; Oh, C.H. Synthesis and inhibitory effects of triarylpyrazoles on LPS-induced NO and $\mathrm{PGE}_{2}$ productions in RAW 264.7 macrophages. Med. Chem. Res. 2017, 26, 2161-2171. [CrossRef]

42. Abdel-Maksoud, M.S.; Kim, M.R.; El-Gamal, M.I.; Gamal El-Din, M.M.; Oh, C.H. Design, synthesis, in vitro antiproliferative evaluation, and kinase inhibitory effects of a new series of imidazo[2,1-b]thiazole derivatives. Eur. J. Med. Chem. 2015, 95, 453-463. [CrossRef] [PubMed]

43. Gamal El-Din, M.M.; El-Gamal, M.I.; Abdel-Maksoud, M.S.; Yoo, K.H.; Oh, C.-H. Design, synthesis, broad-spectrum antiproliferative activity and kinase inhibitory effect of triarylpyrazole derivatives possessing arylamides or arylureas moieties. Eur. J. Med. Chem. 2016, 119, 122-131. [CrossRef] [PubMed]

Sample Availability: Samples of the final compounds are available from the authors.

(C) 2018 by the authors. Licensee MDPI, Basel, Switzerland. This article is an open access article distributed under the terms and conditions of the Creative Commons Attribution (CC BY) license (http:// creativecommons.org/licenses/by/4.0/). 